\title{
Current findings and future prospective of high-value trans Himalayan medicinal plant Lycium ruthenicum Murr: a systematic review
}

Rajni Sharma ${ }^{1}$, Rinky Raghuvanshi ${ }^{2}$, Raj Kumar $^{1}$, Mohan Singh Thakur ${ }^{1}$, Santosh Kumarr ${ }^{1}$, Manoj K. Patel ${ }^{1}$, O. P. Chaurasia ${ }^{1}$ and Shweta Saxena ${ }^{1 *}$

\begin{abstract}
Background: The genus Lycium is commercially known for its nutrient dense goji-berries, among these berries, black goji-berries obtained from Lycium ruthenicum Murr are highly valued and widely used as traditional medicine in trans-himalayan cold desert Ladakh and as functional food in several countries.

Methods: The current collection of data and literature was done by exploring different scientific portals like SciFinder, Google scholar, PubMed, Dictonary of Natural Products, Institute for Scientific Information, Web of Science and Scopus by searching keywords like black goji berry, crystal pearl, and trans-Himalayan plant.

Results: Fruits of L. ruthenicum Murr, are overwhelmingly enriched in anthocyanins, proanthocyanidins, polysaccharides, spermine and spermidine alkaloids. The presence of these bioactive phyto-chemicals has been linked with reported antidiabetic, anti-inflammatory, anti-fatigue, anti-atherosclerosis and neuro-protective properties of black goji berries. A unique color of these berries makes them exceptional as compared to other berries.
\end{abstract}

Conclusions: In this article, we have reviewed the variety of high value phytochemicals of Lycium ruthenicum Murr, with a special focus on health promoting anthocyanins which will provide an insight to the readers for exploring novel applications of $L$. ruthenicum Murr in field of medicine and food industries.

Keywords: Trans Himalayan, Lycium ruthenicum Murr , Anthocyanin, Anti-oxidant, Anti-inflammatory, Neuroprotective, Black gojiberry

\section{Background}

For thousands of years in Southeast Asia, more precisely in China, the Lycium genus has been a valued source of medicines and nutrients. This genus carries perennial flowering plants in the family Solanaceae and has 97 species and 6 varieties predominantly distributed across South America, South Africa, China and a few species in temperate Europe and Asia [1]. Among them, only

\footnotetext{
*Correspondence: shweta.dipas@gmail.com

'Defence Institute of High Altitude Research (DIHAR), Defence Research and Development Organization DRDO), Ministry of Defence, C/o 56 APO,

Leh-Ladakh, Jammu \& Kashmir 901205, India

Full list of author information is available at the end of the article
}

twelve species have been studied to date, out of which three species, viz. L. chinese, L. barbarum and L. ruthenicum Murr are highly valued for their medicinal properties. Due to presence of plethora of biological active compounds, this genus has gained attention in recent years. The berries of $L$. barbarum and $L$. chinese are red colored while those of L. ruthenicum Murr are of purple-black color, all these are commonly known as Goji-berry or wolfberry. $L$. barbarum and $L$. Chinese are well- studied plants and have been found to possess various therapeutic properties like anti-glaucoma, immune-regulatory, antitumor, anti-oxidant, anti-aging, neuroprotective and blood
Springer Open
(๑) The Author(s). 2022 Open Access This article is licensed under a Creative Commons Attribution 4.0 International License, which permits use, sharing, adaptation, distribution and reproduction in any medium or format, as long as you give appropriate credit to the original author(s) and the source, provide a link to the Creative Commons licence, and indicate if changes were made. The images or other third party material in this article are included in the article's Creative Commons licence, unless indicated otherwise in a credit line to the material. If material is not included in the article's Creative Commons licence and your intended use is not permitted by statutory regulation or exceeds the permitted use, you will need to obtain permission directly from the copyright holder. To view a copy of this licence, visit http://creativecommons.org/licenses/by/4.0/. 
sugar level reducing activities to name a few while $L$. ruthenicum Murr remains a relatively under-studied plant of the genus [2]. Its unique violet-black appearance make it more promising in respect of nutritional food as well as a potent candidate for health promoting effects in world.

The present review compiles available information concerning phyto-fingerprinting, geographical distribution in the Indian Himalayan region, and traditional medicinal uses of $L$. ruthenicum Murr with a special focus on its natural habitat in Jammu, Kashmir and Ladakh regions in India till date, earlier Wang et al [3] studies were mainly focused on Chinese medicinal uses and restricted to China only thus it create our necessity to compile this review aimed at providing comprehensive and current information regarding the pharmacological potentials of Lycium ruthenicum Murr based on its geographical location too. The present review critically analyzes the findings of scientific studies conducted on $L$. ruthenicum Murr to date and presents detailed phytochemistry of its bioactive compounds along with their respective pharmacology. For this purpose, a total of 106 scientific references have been studied and compared to compile the present review.

\section{Habitat and botanical characteristics}

The population of L. ruthenicum Murr is localized to the areas of central Asia, Turan and generally dispersed in SW Asia, Europe and America. In Asia, it is distributed from China (Gansu, Nei Mongol, Ningxia, Qinghai, N Shaanxi, Xinjiang, Xizang) to Afghanistan, Pakistan, Russia, Tajikistan, Turkmenistan, Uzbekistan and Indian Himalayas [4]. In India only two species, viz. L. ruthenicum Murr and L. barbarum have been reported date. $L$. ruthenicum Murr is widely distributed in the TransHimalayan Ladakh region at an altitude of 3063-3196 m $(3435.28$ ' N, 07727.48 'E) above mean sea level, chiefly growing on roadsides of Hunder and Udmaru areas of Nubra valley where it is locally known as 'Khizer' [5]. The earliest floristic record of L. barbarum mentioned that it is an endemic plant of Kashmir, India, and supposed to be the "Wozej Beri" (http:// chenabindustries.blogspot.com/2018/07/goji-berrylycium-barbarum-plant-india.html). Lycium ruthenicum Murr is a long-lived, deciduous, perennial and thorny shrub that belongs to the nightshade plant family, i.e. Solanaceae (Fig. 1). It can grow up to $2 \mathrm{~m}$ and has small sessile leaves; zig- zagged bending of stems, internodes with short thorns and extensive roots [6-8].

The hermaphrodite funnel- shaped flowers are palepurple in color and are pollinated by bees (PFAF Plant Database One to two flowers are found on short shoots with $5-10 \mathrm{~mm}$ pedicel with the campanulated calyx of the size of $4.5 \mathrm{~mm}$ that are irregularly lobed and are ciliated. The seeds of $L$. ruthenicum Murr germinate during the late spring or early summer season, while the bushes
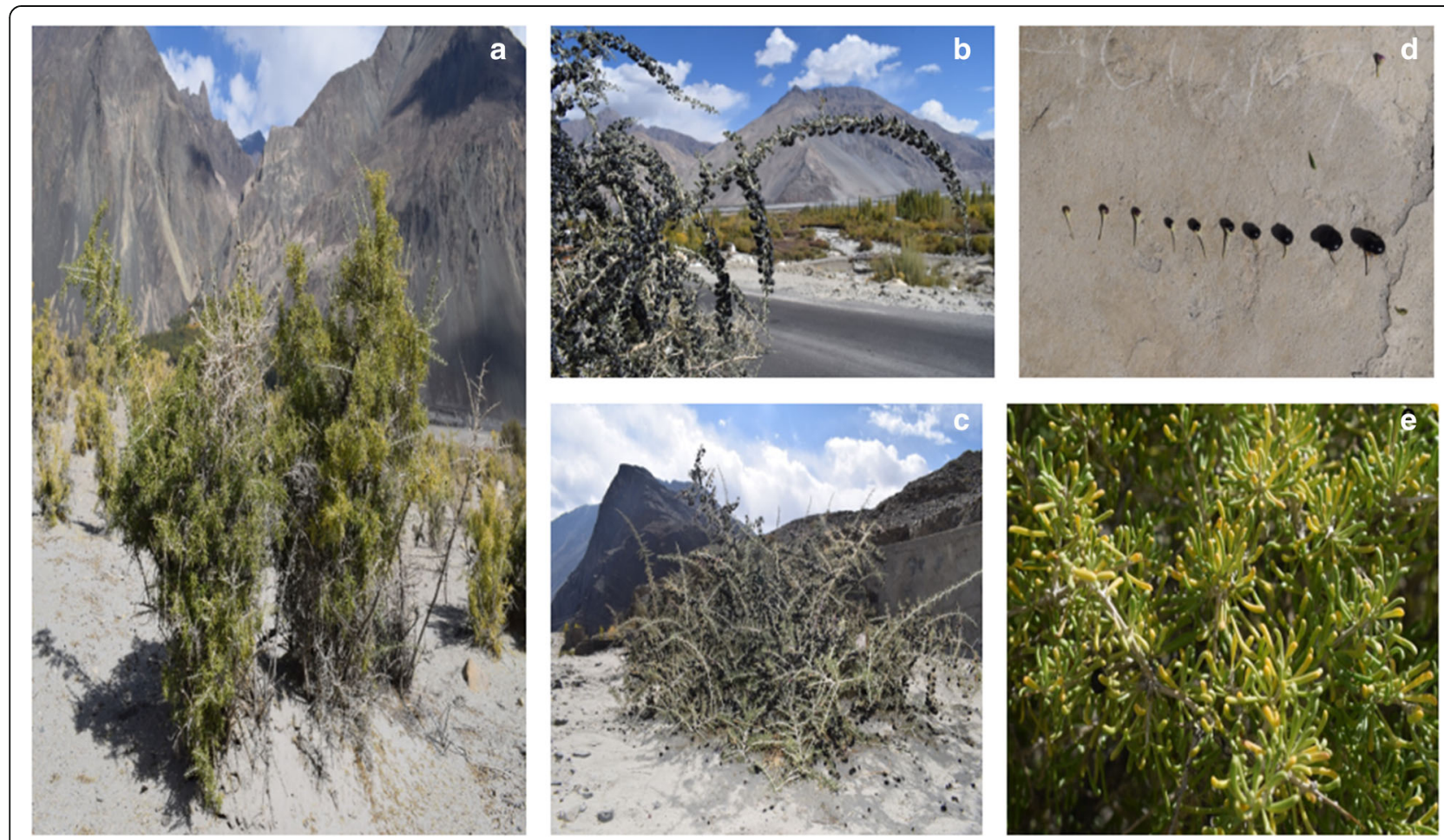

Fig. 1 a. Lycium ruthenicum Plant b \& c. Plant with ripen Fruits d. Developmental stages of Fruit e Close up view of leaves 
flower during months of June-July and fruits are borne during August-September [5]. The fruits are 6-9 mm long, black-purple ellipsoid berries, commonly called black goji berry (Fig. 1). Being a native of an arid environment, this plant prefers well-drained soil and can grow in nutritionally poor soil which makes it an extremely draught and salt-resistant $[9,10]$.

\section{Local and traditional uses}

These dark violet purple color berries have been recorded in the classic Tibetan pharmacological book "Crystal Pearl of Materia Medica" and in Chinese medical monographs as Jing Zhu Ben Cao" and "Si Bu Yao Dian" [11]. In India, these berries have been used by Amchi in various herbal formulations as medicine or as a coloring agent [12]. It has been reported that traditionally the fruits have been used as remedies for the treatment of many diseases such as heart diseases, abnormal menstruation, urethral stones, tinea, furuncle, hypertension, menopause, treatment of blindness in camels in mountain communities especially in the Chinese and Tibet medicine systems [11-16]. while leaves are used as diuretic agent to remove blocked urine [17]. The berries have been endorsed as one of the richest known sources of anthocyanins, essential oils, organic acids, trace minerals and polysaccharides have long been used as traditional functional food and used as a herbal tea too (Organic-Natural-Wolfberry-Ruthenicum-Berries/dp/B07P3VGK25).

Even in modern pharmacological research, it's utility as an anti-atherosclerotic, anti-oxidant, cell-mediated immuneenhancer, anti-tumorogenic, hepatic-function protector, anti-fatigue, anti-aging, hypolipidemic and hypoglycemic agent [18]. Although, scientific validation of such medicinal use is missing till date. Most of these traditional uses are based on folk experiences passed over generations without a scientific understanding of the underlying biological mechanism and detailed structure-activity relationship (SAR) of its key bioactive phyto-compounds warranting indepth scientific studies on biological mechanisms and activities of specific phytoconstituents. Only recently some of the biological activities of berries have been studied in preclinical experimental settings discussed below.

\section{Phytochemical composition and their pharmacological activities}

Though limited in number, few research reports are available that describe the phytochemical profile of the Lycium ruthenicum Murr, the same has been compiled in Table 1 . The reported chemical constituents majorly include anthocyanins, proanthocyaninidins, carotenoids, fatty acids and essential oils, coumarins and cinnamate derivates, polysaccharides, alkaloids and phenolic acids. Among all these, the anthocyanins, which fall under the flavonoids class of compounds, are the most bioactive chemical constituents responsible for most of the reported medicinal
Table 1 Class of Compounds and their percentage of Black Goji Berry

\begin{tabular}{lll}
\hline Class of compound & Percentage & References \\
\hline Polysaccharide & $10.3 \%$ & {$[19]$} \\
Anthocyanins & $2.29 \%$ & {$[20]$} \\
Polyphenols & $3.94 \%$, & {$[3]$} \\
Flavanoids & $4.29 \%$ & {$[3]$} \\
Proanthocyaninidins & $3.42 \%$ & {$[21]$} \\
Protein & $10.76 \%-14.72 \%$, & {$[3]$} \\
Carbohydrate & $69.55 \%-77.14 \%$ & {$[3]$} \\
Fat & $3.90 \%-6.89 \%$ & {$[3]$} \\
SFA & $19.43 \%$ & {$[22]$} \\
Unsaturated fatty acid & $73.00 \%-85.29 \%$ & {$[20]$} \\
MUFA & $21.47 \%$ & {$[22]$} \\
PUFA & $59.10 \%$ & {$[22]$} \\
Aminoacids & $7.459 \%-10.514 \%$ & {$[20]$} \\
Ash & $6.63 \%-10.99 \%$ & {$[20]$} \\
Carotenoids & $0.084 \%$ & {$[23]$} \\
\hline
\end{tabular}

properties of L. ruthenicum Murr [3]. A comparison of anthocyanin content in L. ruthenicum Murr concerning other known sources of anthocyanins is given in Table 2. Their unique color makes them more valuable, due to scarcity of these berries in China; their price is 10 times of red goji berries [30].

\section{Nutritional enrichment}

The fruit of L. ruthenicum Murr has been reported to contain $\gamma$-Vitamin $E(V E,(0.0075 \mathrm{mg} / \mathrm{g})$ and $\delta$-Vitamin $\mathrm{E}$ (VE) $(0.016 \mathrm{mg} / \mathrm{g})$. Also, the oil from L. ruthenicum Murr

Table 2 Anthocyanins content of different plant's Berries

\begin{tabular}{lll}
\hline Source & Content & References \\
\hline Black Goji Berry & $9.28-82.58 \mathrm{mg} / \mathrm{gDW}$ & {$[24,25]$} \\
Purple sweet Potato & $0.82-1.38 \mathrm{mg} / \mathrm{g} \mathrm{DW}$ & {$[26]$} \\
Cornelian cherry & $2.23 \mathrm{mg} / \mathrm{g} \mathrm{FW}$ & {$[26]$} \\
Blackberry & $10.4-19.8 \mathrm{mg} / \mathrm{g} \mathrm{FW}$ & {$[26]$} \\
Red currant, & $0.07 \mathrm{mg} / \mathrm{g} \mathrm{FW}$ & {$[26]$} \\
Mullberry & $1.2 \mathrm{mg} / \mathrm{g} \mathrm{DW}$ & {$[27]$} \\
Bilberry* & $300 \mathrm{mg} / \mathrm{g} \mathrm{FW}$ & {$[28]$} \\
Blackberry & $82-326 \mathrm{mg} / \mathrm{g} \mathrm{FW}$ & {$[28]$} \\
Blueberry & $25-495 \mathrm{mg} / \mathrm{g} \mathrm{FW}$ & {$[28]$} \\
Cranberry & $67-140 \mathrm{mg} / \mathrm{g} \mathrm{FW}$ & {$[28]$} \\
Lingonberry & $77 \mathrm{mg} / \mathrm{g} \mathrm{FW}$ & {$[28]$} \\
Raspberry & $99 \mathrm{mg} / \mathrm{g} \mathrm{FW}$ & {$[28]$} \\
Redcurrant & $22 \mathrm{mg} / \mathrm{g} \mathrm{FW}$ & {$[28]$} \\
Strawberry & $54 \mathrm{mg} / \mathrm{g} \mathrm{FW}$ & {$[28]$} \\
Black grapes & $4.97-8.42 \mathrm{mg} / \mathrm{g} \mathrm{FW}$ & {$[29]$} \\
\hline
\end{tabular}


is known to be rich in $\alpha-\mathrm{VE}, \gamma-\mathrm{VE}$ and $\delta$-VE, the reported values of these are $0.1906,1.8939$ and $0.045 \mathrm{mg} / 100 \mathrm{~g}$, respectively. Among these leucine, methionine, isoleucine and phenylalanine are present at a significantly higher level compared to other amino acids Overall, these tiny berries are nutritionally dense and offer a holistic package of health promoting phytonutrients [31, 32].

\section{Polysaccharides (1-7)}

Polysaccharides are the functional components found in the fruits of the Lycium genus and have been extensively studied for their therapeutic merits. The polysaccharides in L. ruthenicum Murr berries constitute nearly 10 to $17 \%$ of the total dry weight $[19,32,33]$. Several polysaccharides from L. ruthenicum Murr (LRPs) have been isolated and purified from aqueous extracts of fruits using various methods such as anion-exchange chromatography, gel filtration chromatography, high-performance gel permeation chromatography and high-performance liquid chromatography (HPLC) [3]. Their structural composition has been studied by analytical and chemical methods, including methylation analysis, partial acid hydrolysis, IR (infrared spectroscopy), 1D and 2D NMR (nucleic magnetic resonance) and ESI-MS (electrospray ionization mass spectrometry), gas chromatography. These polysaccharides are complex glycopeptides consisting of hetero-polysaccharides and proteins. Various LRPs isolated and characterized from crude L. ruthenicum Murr have been described earlier by Wang et al [3] with their molecular mass, yield and structural composition which includes water-soluble glycoconjugate polysaccharide LRGP1 with molar mass $56.2 \mathrm{kDa}$, an arabinogalactan-protein LRGP3 with a molecular mass of $75.6 \mathrm{Kd}$ LRP4-A with a molecular mass of $1.05 \times 10^{5} \mathrm{Da}$, LRP4-A and LRGP5 from fruit extract [34-37]. Researchers had isolated another immunological active polysaccharides named LRLP4-A with a molecular mass of $135 \mathrm{kDa}$ from leaves of L. ruthenicum Murr [38]. In our section we have described two more polysaccharides isolated from the fruit extract i.e LRP-S2A with a relative molecular weight of $2.65 \times 106 \mathrm{Da}$ and an uronic acid content of $41.8 \%$, contained Rha, Ara, Gal, Glc and GlcA in a molar ratio of 1.00: 2.07: 0.57: 2.59: 4.33 was composed of a backbone consisting of 6-O-Me- $\alpha-(1 \rightarrow 4)$-D-GlcpA, 2 -O-acetyl- $\alpha-(1 \rightarrow 4)$ D-Glcp, $\alpha-(1 \rightarrow 2,4)$-L-Rhap, $\beta$-(1 $\rightarrow 3)-D-G a l p$ and $\alpha-(1 \rightarrow$ $3,5)-\mathrm{L}-\mathrm{Araf}$, and some branches consisting of $6-\mathrm{O}-\mathrm{Me}-\alpha-$ $(1 \rightarrow 4)$-D-GlcpA and terminal $\alpha$-L-Araf [39]. Another homogeneous polysaccharide, LRP3-S1 with a relative molecular weight of $114.8 \mathrm{kDa}$ was purified by anion-exchange chromatography on DEAE Sepharose ${ }^{\mathrm{Tu}}$ fast flow and sephacryl $\mathrm{S}^{-300}$ HR column by Zhang et al. [33]. All LRPs isolated and characterized from $L$. ruthenicum have been compiled in Table 3. Given well- established safety and therapeutic merits of plant-based polysaccharides, $L$. ruthenicum Murr holds promise as an enriched source of
Table 3 Isolated Polysaccharides in fruit and Leaves of Black Goji berries

\begin{tabular}{llll}
\hline S.No & Polysaccharides & Source & References \\
\hline 1. & LRGP1 & Fruit & {$[34]$} \\
2. & LRGP-3 & Fruit & {$[35]$} \\
3. & LRP4-A & Fruit & {$[36]$} \\
4. & LRGP5 & Fruit & {$[37]$} \\
5. & LRLP4-A & Leave & {$[38]$} \\
6. & LRP3-S1 & Fruit & {$[33]$} \\
7. & LRP-S2A & Fruit & {$[39]$} \\
\hline
\end{tabular}

bioactive polysaccharides and thus calls for a more intense analytical investigation.

\section{Alkaloids (8-42)}

They are one of the large groups of organic compounds that usually contain at least one nitrogen atom in a heterocyclic ring occurring chiefly in the flowering plants. The presence of nitrogen makes them alkaline. Based upon their respective structures, they can be divided into various types like indoles, quinolines, isoquinolines, pyrrolidines, pyridines, pyrrolizidines, tropanes etc [40]. There have been concerns regarding the presence of certain alkaloids, viz. atropine and hyoscyamine, in other members of the Lycium genus, i.e. L. halimifolium and L. europaeum, although these compounds are found in concentrations far below their reported toxic doses. However, the presence of such toxic tropane alkaloids has not been reported in L. ruthenicum Murr to date. Naturally occurring polyamines are one of the classes of alkaloids that are involved in cell multiplication and its regulation in plants. L. ruthenicum Murr is the rich source of spermidine or spermine alkaloids, a pharmacologically important class of alkaloids reported to protect heart from aging, lowering of blood pressure and helpful in fruit ripening. Earlier 24 alkaloids have been reported by Wang et al [3], herein, we have reported some more spermidine or spermine alkaloids from black goji berry. A total of 36 spermine and spermidine has been compiled in Table 4 and Figs. 2 and 3 [43, 44].

\section{Fatty acids and essential oil (43-78)}

Plant-based fatty acids and essential oils are always been valued for their pharmacological utilities such as improving immunity, brain health, mood, cell signaling regulation and reducing inflammation etc. Chi et al [22] studied the lipophilic compound composition of $L$. ruthenicum Murr seed and fruit essential oil in the samples collected from the Qinghai-Tibetan Plateau in China. Both the essential oils were shown to contain saturated, monounsaturated (MUFA), and polyunsaturated fatty acids (PUFA) with a predominance of linoleic, oleic 
Table 4 Identified Alkaloids in Black goji berry

\begin{tabular}{|c|c|c|}
\hline Sr.No & Alkaloids & References \\
\hline 8. & $\mathrm{~N}, \mathrm{~N}$-bis (dihydrocaffeoyl) spermine & [41] \\
\hline 9. & tris-(Dihydrocaffeoyl) spermine & [41] \\
\hline 10. & $N^{1}, N^{14}$-bis-(Dihydrocaffeoyl) spermine & {$[18,41]$} \\
\hline 11. & $\mathrm{~N}$-Caffeoylspermidine & [18] \\
\hline 12. & $\mathrm{~N}^{1}, \mathrm{~N}^{10}$-bis-(Caffeoyl) spermidine hexose & {$[18]$} \\
\hline 13. & $N^{1}, N^{10}$-bis-(Caffeoyl) spermidine dihexose & [18] \\
\hline 14. & $\mathrm{~N}^{1}$-Caffeoyl- $\mathrm{N}^{10}$-dihydrocaffeoyl spermidine hexose & {$[18,41]$} \\
\hline 15. & $\mathrm{~N}^{1}$-Dihydrocaffeoyl- $\mathrm{N}^{10}$-caffeoyl spermidine & [18] \\
\hline 16. & $\mathrm{~N}^{1}$-Caffeoyl- $\mathrm{N}^{10}$-dihydrocaffeoyl spermidine & [18] \\
\hline 17. & $N^{1}$-Dihydrocaffeoyl- $N^{10}$-coumaroyl spermidine & [18] \\
\hline 18. & $\begin{array}{l}\text { 7'-O-[3-D-glucopyranose]-N } N^{1}, N^{10} \text { didihydrocaffeoyl- } \\
\text { spermidine }\end{array}$ & {$[42]$} \\
\hline 19. & $\begin{array}{l}\text { 7'-O-[3-D-glucopyranose]- } \mathrm{N}^{1} \text {-dihydrocaffeoyl- } \mathrm{N}^{3} \text { - } \\
\text { caffeoylspermidine }\end{array}$ & [42] \\
\hline 20. & 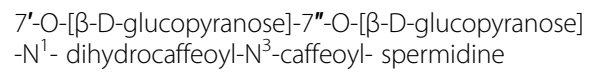 & [42] \\
\hline 21. & $N^{1}$-caffeoyl- $N^{3}$-dihydrocaffeoyl spermidine & [3] \\
\hline 22. & N,N-bis (dihydrocaffeoyl) spermidine hexoside & [3] \\
\hline 23.. & (dihydrocaffeoyl) caffeoyl spermidine hexoside & [3] \\
\hline 24. & $\mathrm{~N}, \mathrm{~N}$-dicaffeoyl-spermidine & [3] \\
\hline 25. & Caffeoyl (dihydrocaffeoyl) spermidine isomers & [3] \\
\hline 26 & N-Caffeoyl, N'-dihydrocaffeoyl spermidine dihexose & [3] \\
\hline 27. & Lyrium spermidine A & [18] \\
\hline 28. & N-Feruloylagmatine & [18] \\
\hline 29 & N-Monocinnamoyl-putrescine & [3] \\
\hline 30. & N1 -caffeoyl spermidine & {$[43]$} \\
\hline 31. & N10-dihydrocaffeoyl spermidine hexose & [43] \\
\hline 32. & N1 -Dihydrocaffeoyl & [43] \\
\hline 33. & N10 - caffeoyl spermidine hexose & [43] \\
\hline 34. & N1, N10-dihydrocaffeoyl spermidine hexoside & {$[43]$} \\
\hline 35. & N1,N10-bis (dihydrocaffeoyl)spermidine & [44] \\
\hline 36. & $\mathrm{~N}$-trans-coumaroyltyramine & [44] \\
\hline 37 & $\mathrm{~N}$-trans-feruloyltyramine & [44] \\
\hline 38. & N-trans-feruloyl 3'-O-methyldopamine & [44] \\
\hline 39. & $\mathrm{~N}$-trans-feruloyloctopamine & [44] \\
\hline 40. & $\mathrm{~N}$-cis-coumaroyltyramine & [44] \\
\hline 41. & $\mathrm{~N}$-cis-feruloyltyramine & [44] \\
\hline 42. & N-cis-feruloyloctopamine & [44] \\
\hline
\end{tabular}

and palmitic acids. It is worth mentioning here that linoleic acid is an essential fatty acid with a key role in the eicosanoid synthesis pathway as a precursor of arachidonic acid [47]. Earlier review had compiled 25 fatty acids and essentials oils, we have reported total of 36 fatty acids and essentials oils where the key fatty acids from L. ruthenicum Murr oil included linoleic, oleic, palmitic, linolenic and stearic acids which together comprised $95.59 \%$ of the total fatty acids. According to literature the comparative ratio of PUFAs, MUFAs and SFs in berries and seed oil are (59.10\%: 63.99\%), (21.47\%: 21.76\%),(19.43\%: 14.26\%) [45, 46] (Fig. 3 and Table 5).

\section{Phytosterols (79-87)}

Phytosterols are cholesterol-like molecules found in all plant foods, with the highest concentrations occurring in vegetable oils. They are absorbed only in trace amounts but inhibit the absorption of intestinal cholesterol including recirculating endogenous biliary cholesterol, a key step in cholesterol elimination. The sterol composition has been used as an important marker to mark the geographical locations of various goji berry samples (including L. chinense and L. barbarum) using linear discriminant analysis (LDA) and principal component analysis (PCA) [48]. In our study, we have compiled total nine phytosterols isolated from seed oil of L.ruthenicum Murr (Table 6 and Fig. 4), which were not analyzed in previous studies [46]. The total content of phytosterol was approx $489.2 \mathrm{mg} / 100 \mathrm{~g}$ samples of black gojiberries which majorly consisted of stigmasterol, campesterol and $\beta$-sitosterol. Additionally, the Vitamin A and E contents were $0.3 \mathrm{mg} / 100 \mathrm{~g}$ and $46.3 \mathrm{mg} / 100 \mathrm{~g}$ in tested samples, proposing the blackberry vegetable oil worth exploration for further development.

\section{Carotenoids (88-93)}

Carotenoids are a class of phytonutrients ("plant chemicals") belonging to the terpenoid family, called tetraterpenoids. They are yellow, orange and red- colored pigments that are produced by plants, algae, several bacteria and fungi. Zeaxanthin, $\beta$-cryptoxanthin, $\beta$-carotene are some of the common carotenoids which have been reported from L. ruthenicum Murr and play a crucial antioxidant function of deactivating free radicals such as single oxygen atoms that can damage cells by reacting with other bio-molecules. As expected owing to its black-purple color, the black goji berry from Qinghai Province in China showed a much lower carotenoid content $(1.51-3.19 \mu \mathrm{g} / \mathrm{g})$ compared to red goji berry $(212.24-233.08 \mu \mathrm{g} / \mathrm{g})[23,24]$. In a very interesting study by Liu Y et al. [49], it was shown that undetectable carotenoid content in black goji berry is due to lack of chromoplast biosynthesis and not due to inactivation of carotenoid biosynthesis pathway during fruit ripening. Since, chromoplasts are the reservoirs for colored pigments, in absence of these in L. ruthenicum Murr fruits and overexpression of carotenoid cleavage dioxygenase 4 enzyme leads to continuous degradation of carotenoids. The carotenoids reported from gojiberries have been compiled in Table 7 and Fig. 5. 


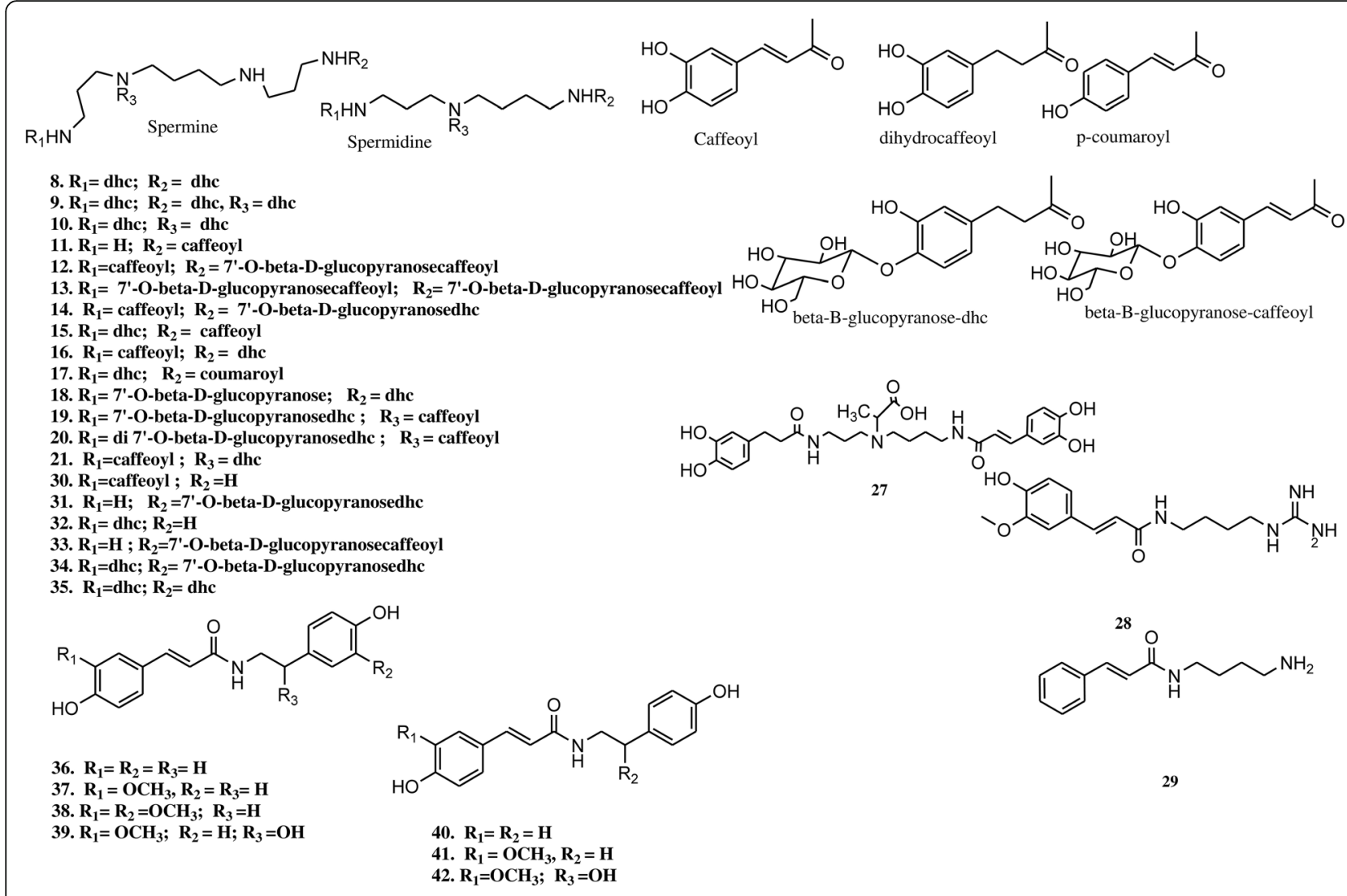

Fig. 2 Representative Structure of Alkaloids

\section{Phenolic acid and flavonoids (94-133)}

As discussed in detail in forthcoming sections, the black goji berries have been repeatedly shown to possess significantly higher anti-oxidant properties than other closely related gojiberries, i.e. L. barbarum and L. chinense despite their much lower carotenoid contents. Research studies have established the supremacy of phenolic compounds, such as condensed tannins, phenolic acids and flavonoids as contributors to plant's antioxidant capacities [50]. Different extraction methods have been followed for the detection of different phenolic acids in L. ruthenicum Murr samples such as ultrasonic-assisted extraction using the surface methodology, UPLC-Q-Orbitrap MS etc. Observations of significantly higher total phenolic content $(8.33 \mathrm{mg}$ GAE/ g), total flavonoid content (11.09 mg CAE/g) and condensed tannins $(20.87 \mathrm{mg} \mathrm{CAE} / \mathrm{g}$ ) in black goji berry samples than in red goji berry (3.16 mg GAE/g, $2.83 \mathrm{mg}$ $\mathrm{CAE} / \mathrm{g}$ and $1.08 \mathrm{mg} \mathrm{CAE} / \mathrm{g}$ ) respectively is a highly convincing $[24,51]$. Since retention of these superior antioxidant properties in dried black goji berries is a highly desired feature for its commercialization as a functional food, the effect of different drying methods on the content of polyphenols has been extensively studied by several researchers $[52,53]$. It has been concluded that the contents of total polyphenols remain highest by the airdrying method as compare to other methods viz. lowtemperature oven drying and vacuum freeze- drying. Table 8 gives details of the forty phenolic acid and flavonoids detected in black goji berry to date and their respective structures have been shown in Fig. 6.

\section{Coumarins and Cinamate derivatives (134-136)}

Coumarins act as an antioxidants, enzyme inhibitors, and precursors of toxic substances. In addition to biological activities, they are used as additives in food, cosmetics and optical brightening agents [55]. The phytochemical investigation of ethyl acetate extract of black goji berry has lead to the isolation of two coumarins (Scopoletin and Esculetin) and Methyl-2-hydroxy-4undecanoxy-trans- cinamate which was characterized by ${ }^{1} \mathrm{H}-\mathrm{NMR},{ }^{13} \mathrm{C}$-NMR and FT- IR spectroscopic data, MS spectrometry, elemental analysis and by comparison with the literature values [56]. Table 9 gives the details of these derivatives and structures are described in Fig. 7.

\section{Anthocyanins and Proanthocyanidins (137-185)}

The most important bioactive constituents of $L$. ruthenicum Murr are anthocyanins which are a large family of naturally occurring water-soluble plant pigments 


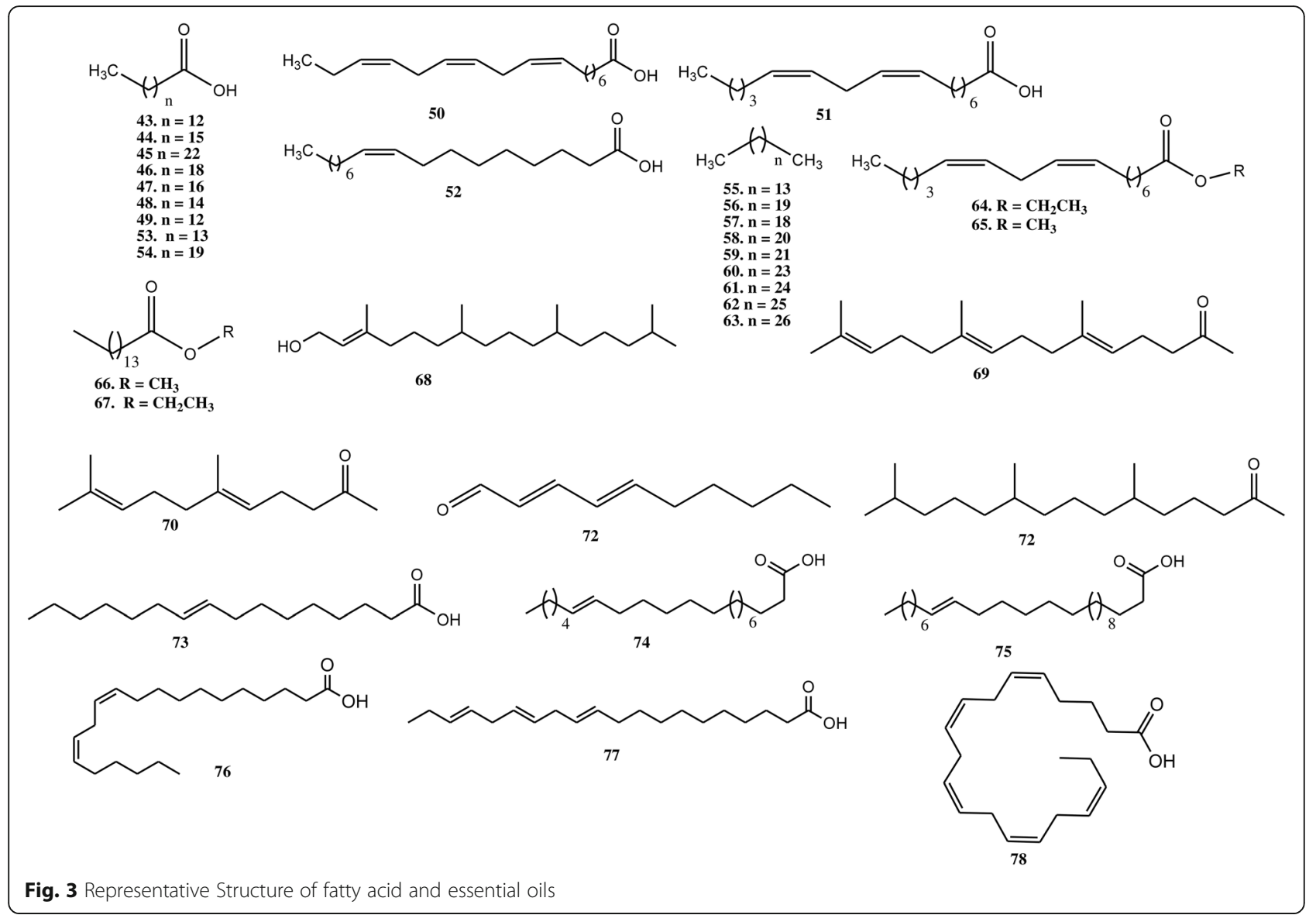

including glycoside or acyl glycoside anthocyanidins. They belong to the flavonoids class of compounds. They are found in the vacuolar sap of the epidermal tissues of fruits and flowers. These pigments belong to the most common class of phenolic compounds that share the same basic flavonoid structure with a positively charged oxygen atom at the c-ring of the structure connected with sugar moieties [57]. These sugar moieties are primarily monosaccharides and disaccharides like glucose, rhamnose, galactose, arabinose, sambubiose, rutinose, and sophorose, which are further acylated by organic acids like acetic acid, oxalic acid, phenolic acids such as p-coumaric acid, p-cinnamic acid and ferulic acid etc. The core structure of all anthocyanins remains a phenolated benzopyran referred to as flavylium cation (2-phenylchromenylium) which is described as a C6-C3-C6 skeleton. These pigments are responsible for the blue, purple, red and intermediate colours based on the $\mathrm{pH}$ of the microenvironment. They are widely used as nutraceuticals and found in our daily diets especially in berries, thus are extensively consumed by humans among all the flavonoids $[58,59]$.

These berries are also an affluent source of healthpromoting proanthocyanidins and claimed to be richer than malts and hops. A recent study revealed that on addition L.ruthenicum Murr berries in beer improved the content of proanthocyanidin from 10 to $68 \mathrm{mg} / \mathrm{L}$ in finished beer, and the total polyphenol content in beer was increased from 246 to $457 \mathrm{mg} / \mathrm{L}$ [21].

Although the total flavonoid content in L. ruthenicum Murr is lower as compared to $L$. chinense and $L$. barbarum but its anthocyanin content is higher. In fact, in case of $L$. barbarum, anthocyanins have not been detected at any stage of the fruit development [60]. Among the chemical constituents of L. ruthenicum Murr fruit, the most well- researched component is the group of water-soluble anthocyanins, which are estimated to comprise approx $2.3 \%$ of the dried fruits [61]. It has been claimed that black gojiberries are one of the highest anthocyanin- containing natural sources with a maximum reported content of $24.04 \pm 0.07 \mathrm{mg} / \mathrm{g}$ [43]. Several anthocyanins have been isolated and purified from $L$. ruthenicum Murr berry extracts by various extraction methods such as ultrasound-assisted aqueous two-phase extraction (UA-ATPE) and other analytical techniques such as D-101 resin- based column chromatography and high-performance liquid chromatography (HPLC) [25, 42, 62-64]. Ealier total 38 anthocyanins have been 
Table 5 Identified fatty acid and Essential Oil content of Black Goji berries

\begin{tabular}{|c|c|c|c|c|}
\hline Sr. No. & Fatty acid and Essential Oil & Content Percentage (fruits) & Content Percentage (seed) & References \\
\hline 43. & Myristic acid & 0.14 & 0.04 & {$[22]$} \\
\hline 44. & Margaric acid & 0.29 & - & {$[22]$} \\
\hline 45. & Tetracosanoic acid & 0.47 & 0.02 & {$[22]$} \\
\hline 46. & Arachidic acid & 2.48 & 0.21 & {$[22]$} \\
\hline 47. & Stearic acid & 3.56 & 1.40 & {$[45]$} \\
\hline 48 & Heptadecanoic acid & - & 0.07 & [22] \\
\hline 49. & Pentadecenoic acid & 0.01 & 0.01 & {$[22]$} \\
\hline 50. & Linolenic acid & 4.99 & 6.60 & {$[45]$} \\
\hline 51. & Linoleic acid & 59.38 & 74.56 & {$[45]$} \\
\hline 52. & Oleic acid & 20.70 & 11.82 & {$[22]$} \\
\hline 53 & Palmitic acid & 12.49 & 4.88 & {$[22]$} \\
\hline 54. & Docosanoic acid (Behenic acid) & - & 0.06 & {$[46]$} \\
\hline 55. & Hexadecane & 0.8 & - & [3] \\
\hline 56. & Docosane & 1.5 & - & [3] \\
\hline 57. & Heneicosane & 0.9 & - & {$[3]$} \\
\hline 58. & Tricosane & 2.5 & - & {$[3]$} \\
\hline 59 & Tetracosane & 3.9 & - & {$[3]$} \\
\hline 60. & Hexacosane & 7.0 & - & {$[3]$} \\
\hline 61. & Heptacosane & 14.3 & - & {$[3]$} \\
\hline 62 & Octacosane & 5.2 & - & {$[3]$} \\
\hline 63. & Nonacosane & 6.2 & - & {$[3]$} \\
\hline 64. & Ethyl linoleate & 10 & - & {$[3]$} \\
\hline 65. & Methyl linoleate & 5.6 & - & {$[3]$} \\
\hline 66. & Methyl hexadecanoate & 4.5 & - & {$[3]$} \\
\hline 67. & Ethyl hexadecanoate & 5.8 & - & {$[3]$} \\
\hline 68. & Phytol & 3.0 & - & [3] \\
\hline 69. & Farnesylacetone & 4.6 & - & [3] \\
\hline 70. & (E)-Geranylacetone & 1.1 & - & {$[3]$} \\
\hline 71. & (E,E)-2,4-Decadienal & 0.8 & - & [3] \\
\hline 72. & Hexahydrofarnesylacetone & 0.8 & - & [3] \\
\hline 73. & Palmitoleic acid & 0.76 & 0.12 & {$[22]$} \\
\hline 74. & cis-10-Heptadecenoic acid & - & 0.04 & {$[22]$} \\
\hline 75. & cis-11-Eicosenoic acid & - & 0.04 & {$[22]$} \\
\hline 76 & cis-11, 14-Eicosadienoic acid & - & 0.02 & {$[22]$} \\
\hline 77. & cis-11, 14, 17-Eicosatrienoic acid & - & 0.06 & {$[45]$} \\
\hline 78. & n-3 cis-5, 8, 11, 14, 17-Eicosapentaenoic acid & - & 0.01 & {$[45]$} \\
\hline
\end{tabular}

discussed by Wang et al [3], in our study we compiled total 49 anthocyanins included anthocyanidin with their respected structures $[65,66]$ (Table 10 and Fig. 8). These anthocyanins are responsible for the organoleptic flavour of the black-purple colored L. ruthenicum Murr fruits. The predominant anthocyanin is petunidin 3-O-[6-O-(4O-(trans-p-coumaroyl) $-\alpha$-L-rhamnopyranosyl) $\quad-\beta$-Dglucopyranoside] 5-O-[b-glucopyranoside, accounting for the largest proportion of anthocyanins in wolfberry fruits, although the contents varies in samples obtained from different geographical locations [25, 42, 64]. The total anthocyanins content determined by the $\mathrm{pH}$ differential method ranged from $9.28 \pm 1.19$ to $82.58 \pm$ $0.95 \mathrm{mg}$ C3GE/g DW. Five anthocyanidins and five anthocyanins were qualitatively and quantitatively analyzed by Zhang et al [65] among these, 10 constituents (delphinidin-3-glu, cyanidin-3-glu, petunidin-3-glu, peonidin-3-glu, malvidin-3-glu, delphinidin, cyanidin, 
Table 6 Identified phytosterols of Black Goji berries

\begin{tabular}{lll}
\hline Sr. No. & Phytosterol & References \\
\hline 79. & 24-methylenecholesterol & {$[46]$} \\
80. & Campesterol & {$[46]$} \\
81. & Stigmasterol & {$[46]$} \\
82. & dihydrolanosterol & {$[46]$} \\
83. & 24-methyldesmosterol & {$[46]$} \\
84. & $\beta$-sitosterol & {$[46]$} \\
85. & $\Delta 5$-avenasterol & {$[46]$} \\
86. & Cycloartenol & {$[46]$} \\
87. & $\Delta 7$ - avenasterol & {$[46]$} \\
\hline
\end{tabular}

petunidin, pelargonidin and malvidin) were detected. Anthocyanins are well recognized to promote health benefits owing to their potent anti-oxidative, antiinflammatory, anti-carcinogenic, cardio-protective and neuroprotective effects $[70,71]$.

\section{Reported biological activities of L. ruthenicum Murr fruits} As it has already been discussed that L.ruthenicum Murr is rich in many biological active natural compounds which leads its potential towards many pharmacological activity like antioxidant activity due to presence of abundant of polyphenols, anti-fatigue effect due to existence of polysaccharides etc. So, herein we have categorized and described different biological activity reported from L.ruthenicum Murr in depth.

\section{Anti-oxidant effect}

The anti-oxidant properties of L. ruthenicum Murr berries have been most extensively worked out by various researchers in in-vitro and in-vivo study models, especially of the berry extracts, which are known to be rich in anthocyanins content $[41,63,68,72-74]$. These pigments exhibit a noticeable inhibition of lipid oxidation induced by free radicals owing to their strong free radical scavenging activities. L. ruthenicum Murr has higher antioxidant potential as compared to L. barbarum, most obviously owing to a higher anthocyanin content of $L$. ruthenicum Murr in comparison with L. barbarum [24, 51, 75]. Major constituents that were found to be responsible for anti-oxidant properties in several studies are rutin, chlorogenic acid, $\mathrm{p}$-coumaric acid, caffeic acid, syringic acid, dhc-caffeoyl spermidine isomer, quercetino-rut, kaempferol-o- rut, isorhamnetin-o-rut, ascorbic acid, lycium spermidine A, tocopherols, carotenoids, anthocyanins, polysaccharides $[54,61,68]$. In general, plants with higher TPC and TFC show stronger antioxidant activity since there is a positive correlation between total polyphenols and positive findings in DPPH $(2,2-$ diphenyl-1-picrylhydrazyl) and ABTS (2,2'-azino-bis-3ethylbenzothiazoline-6-sulphonic acid) assays [76]. In Lycium plant, the TPC was found to range from $698.14 \pm 27.15$ to $1311.10 \pm 80.05 \mathrm{mg}$ GAE per $100 \mathrm{~g}$ FW, which was significantly higher than those of bayberry fruit extracts (360.3-446.1 mg/100 g FW) and black berry extracts (261.9-929.6 mg per $100 \mathrm{~g}$ FW) [68]. The $\mathrm{DPPH}$ free radical- scavenging activity, ABTS, FRAP<smiles>C=C(CCC(C)C(C)C)C(C)CCC(C)C1CCC2C3CC=C4CC(O)CCC4(C)C3CCC12C</smiles> 
Table 7 Carotenoids content of Red and Black Goji berries

\begin{tabular}{|c|c|c|c|c|}
\hline S.No & Carotenoids & Black goji berry & Red Goji berry & References \\
\hline 88. & Lutein & $10.5 \pm 0.1$ & $52.7 \pm 0.2$ & {$[24]$} \\
\hline 89. & B-Cyptoxanthin & $8.6 \pm 0.1$ & $739.8 \pm 9.6$ & {$[24]$} \\
\hline 90. & Zeaxanthin & $17.01 \pm 0.2$ & $9306 \pm 111.2$ & {$[24]$} \\
\hline 91. & Neoxanthin & $265.5 \pm 2.6$ & $15.6 \pm 1.1$ & {$[24]$} \\
\hline 92. & $\beta$-Carotene & $18.8 \pm 0.9$ & $413.9 \pm 3.5$ & {$[24]$} \\
\hline 93. & Zeaxanthin dipalmitate & 0.031 & 0.214 & {$[23]$} \\
\hline
\end{tabular}

values of fruit extracts were $49.65 \pm 3.1,47.8 \pm 6.6$, $56.3 \pm 6.9 \mathrm{uM} \mathrm{TE} / \mathrm{g}$ FW respectively. The chlorogenic acid $(112.5 \pm 8.4 \mu \mathrm{g} / \mathrm{g} \mathrm{FW})$ was the most abundant phenolic acid found in Lycium [77]. Recently, Fatty acids and mineral contents of L. ruthenicum Murr have showed antioxidant activity against isoproterenol-induced acute myocardial ischemia in mice reported by Nzeuwa et al [45]. The most bioactive constituent, anthocyanin, has been reported to possess an inhibitory effect on tyrosinase monophenolase with $\mathrm{IC}_{50}=1.483 \pm 0.058 \mathrm{mg} / \mathrm{mL}$ by Shen et al. [78]. Petunidin3-O-[6-O-(4-O-(trans-p-coumaroyl)-a-L-rhamnopyranosyl)-b-D-glucopyranoside]-5O-[b-Dglucopyranoside] which belongs to class of anthocyanins isolated from $L$. ruthenicum Murr exhibited higher scavenging activities against ABTS, DPPH and superoxide radicals than the crude extract of anthocyanins. Moreover, this compound has a significant effect on inhibition of the reactive oxygen damage induced by $\mathrm{H}_{2} \mathrm{O}_{2}$ in PC12 cells, reflecting in the recovery of plasma membrane integrity, decreased production of MDA, and increased secretion of antioxidant enzymes (glutathione peroxidase: $146.24 \pm 7.25 \mathrm{mg} /$ protein, superoxide dismutase: $91.83 \pm 5.81 \mathrm{mg} /$ protein and catalase: $23.45 \pm 3.01$ $\mathrm{mg} /$ protein) vitamin $\mathrm{E}$ as a positive control [62]. Chinese researchers have patented black goji berry as a natural composite PCT Int. Appl. (2017). Liu et al [79] had studied the antioxidant scavenging activity of $L$. ruthenicum Murr seed oil by using assays based on three kinds of radicals (DPPH.,. $\mathrm{OH}$ and $\mathrm{O} 2 \cdot$ ) and lipid peroxidation and found that oil had the potential to be a novel antioxidant agent for use in the field of food, pharmaceuticals and cosmetics. Wang et al. [80] has proposed that in vitro gastrointestinal digestion may enhance the biological activities of anthocyanins especially for antioxidant activity and $\alpha$-glucosidase inhibition.

\section{Anti-inflammatory effect}

Inflammation is a well-established cause as well as the effect of the plethora of human diseases, thus the need for dietary as well as pharmaceutical anti-inflammatory entities remains unmet to date. Since L. ruthenicum Murr is naturally packed with potent anti-inflammatory phytocompounds (esp polysaccharides and polyphenols), the invitro and in-vivo efficacy of crude extracts of black goji berry fruits has been evaluated in several animal models of inflammatory diseases. Polysaccharides from natural sources are known to be very potent anti-inflammatory bio-molecules [81, 82]. In-vitro anti inflammatory action of isolated water-soluble arabinogalactan polysaccharide from L. ruthenicum Murr, LRGP3 has been

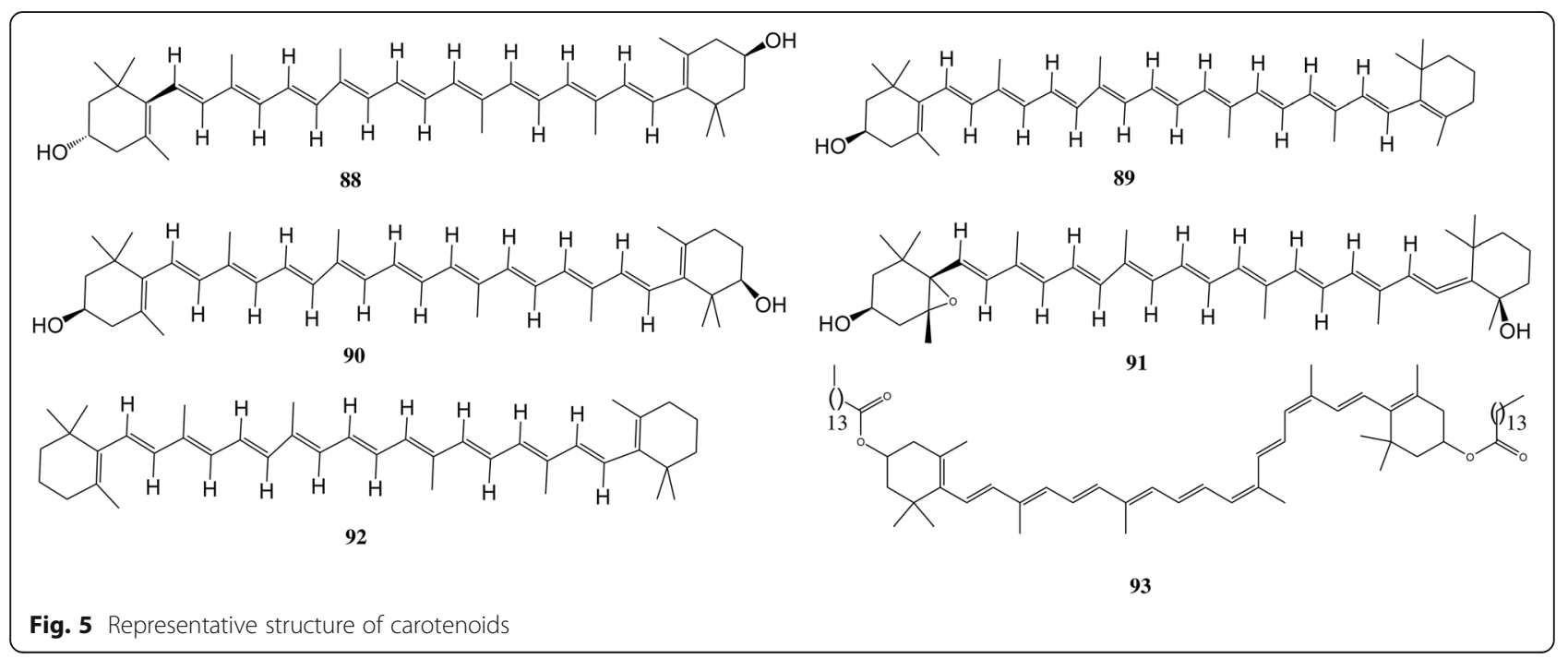


Table 8 Identified Phenolic acid and Flavonoids of Black goji berry

\begin{tabular}{|c|c|c|}
\hline Sr. No. & Phenolic acid and Flavonoids & References \\
\hline 94. & Ampelopsin glucoside & {$[18]$} \\
\hline 95. & Catechin & {$[54]$} \\
\hline 96 & Quercetin & {$[3]$} \\
\hline 97 & Myricetin & {$[3]$} \\
\hline 98. & Quercetin-3-O-rutinoside/ Rutin & {$[18,41]$} \\
\hline 99. & Kaempferol & {$[3]$} \\
\hline 100. & Kaempferol-O-rutinoside & {$[41]$} \\
\hline 101. & Isorhamnetin-O-rutinoside & {$[41]$} \\
\hline 102. & Quercetin-O-rutinoside-hexose & {$[41]$} \\
\hline 103 & Quercetin-rhamno-dihexoside & {$[3]$} \\
\hline 104 & 4-Caffeoylquinic acid & {$[18]$} \\
\hline 105 & 4,5-di-O- caffeoylquinic acid & {$[41]$} \\
\hline 106 & trans- caffeoylquinic acid & {$[41]$} \\
\hline 107 & 1,3-dicaffeoylquinic acid & {$[18]$} \\
\hline 108 & 3,4-di-O- caffeoylquinic acid & {$[41]$} \\
\hline 109 & 3,5-di-O- caffeoylquinic acid & {$[41]$} \\
\hline 110 & trans-neo- caffeoylquinic acid & {$[41]$} \\
\hline 111 & trans-crypto- caffeoylquinic acid & {$[41]$} \\
\hline 112 & 4-(p-cumaroyl)-methyl-L- rhamnoside & {$[3]$} \\
\hline 113 & Caffeic acid & {$[54]$} \\
\hline 114 & p-Coumaric acid & {$[3]$} \\
\hline 115 & Ferulic acid & {$[3]$} \\
\hline 116 & Vanillic acid & {$[3]$} \\
\hline 117 & Protocatechuic acid & {$[3]$} \\
\hline 118 & Syringic acid & {$[54]$} \\
\hline 119 & Chlorogenic acid & {$[3,18,41]$} \\
\hline 120 & Gallic acid & {$[54]$} \\
\hline 121 & Phloretin & {$[53]$} \\
\hline 122 & Protocatechuate & {$[53]$} \\
\hline 123 & Syringate & {$[53]$} \\
\hline 124 & Ellagic acid & {$[53]$} \\
\hline 125 & Naringenin & {$[53]$} \\
\hline 126 & ruthenicunoid $A$ & {$[44]$} \\
\hline 127 & proanthocyanidins-B2 & {$[52]$} \\
\hline 128 & O-hydroxybenzene acetic acid & {$[52]$} \\
\hline 129 & 2,4-dihydroxybenzoic & {$[52]$} \\
\hline 130 & proanthocyanidins-A2 & {$[52]$} \\
\hline 131 & veratronic acid & {$[52]$} \\
\hline 132 & Naringin & {$[52]$} \\
\hline 133 & Hesperidin & {$[52]$} \\
\hline
\end{tabular}

investigated by Peng et al. [37]. The authors reported that LRGP3 could inhibit the expression of iNOS, production of NO and inflammatory cytokines in RAW264 cells and proposed the anti-inflammatory activity to be mediated by the NF- $\beta$-iNOS-NO signaling pathway. A metabolite of LRGP3, i.e. LRGP3-AF, has immune effectors properties viz. significant complement-fixing and macrophage stimulation activities. The galactan backbone of this polysaccharide is shown to be essential for its immunomodulatory activity [83].

The enrichment of anthocyanins in black gojiberry makes it a promising subject for anti-inflammatory activity exploration. In a hyperlipidemia atherosclerosis animal model, L. ruthenicum Murr anthocyanins (doses of $100,200,400 \mathrm{mg} / \mathrm{kg}$ fed for $6 \mathrm{w}$ ) have shown significant improvement in lipid profile, percent aortic plaque area and severity of inflammatory damage in aorta, heart and liver tissue which were promising in comparison to simvastatin drug group [84]. Further, Shu and Hou [85] also endorsed the anti-inflammatory potential of anthocyanin extract of L. ruthenicum Murr in a rat model of carbon tetra-chloride induced hepatic injury. Oral administration of $30 \mathrm{mg}$ L. ruthenicum Murr extract for 7 days, led to significant decrease in the levels of ROS, SGOT and SGPT and pro- inflammatory markers including NO, ROS, IL-1 and IL-6. The Plausible mechanism of action of anthocyanins via RAGE/NF- $\mathrm{kB} / \mathrm{JNK}$ pathway has been explained by Chen $S$ et al [69] in their rat model of $d$ galactose induced memory impairment. In the same study, it has been shown that these black gojiberry anthocyanins could significantly downregulate inflammatory markers, tumor necrosis factor- $\alpha$ (TNF- $\alpha$ ), cyclooxygenase-2 (COX-2), nuclear factor kappa B $(\mathrm{NF}-\mathrm{kB})$ and interleuin-1- $\beta$ (IL-1 $\beta$ ) which are hallmarks of inflammatory diseases. Further, in a separate study, L. ruthenicum Murr ethanol extract inhibited colonic inflammation by regulating mitogen-activated protein kinase (MAPK) pathways and downregulating NF- $\mathrm{kB}$ levels, proposing these black gojiberry as a promising functional food for the management of inflammatory bowel disease (IBD). This in-vivo study was conducted in rat model of dextran sulfate sodium- induced colitis wherein supplementation with berry extracts could suppress activation of (NOD)-like receptor family pyrin domain containing 3 (NLRP3) inflammasome and regulate inflammation-inducing immune cell infiltration [86].

Supplementation with L. ruthenicum Murr has shown promise in a pre-clinical animal model of western diet-induced fatty liver disease. The extracttreated animal group showed reduced triglyceride accumulation and reduced hepatic inflammation [87]. Although in this study, supplementation could not influence the body weight, in a separate study by Yin 


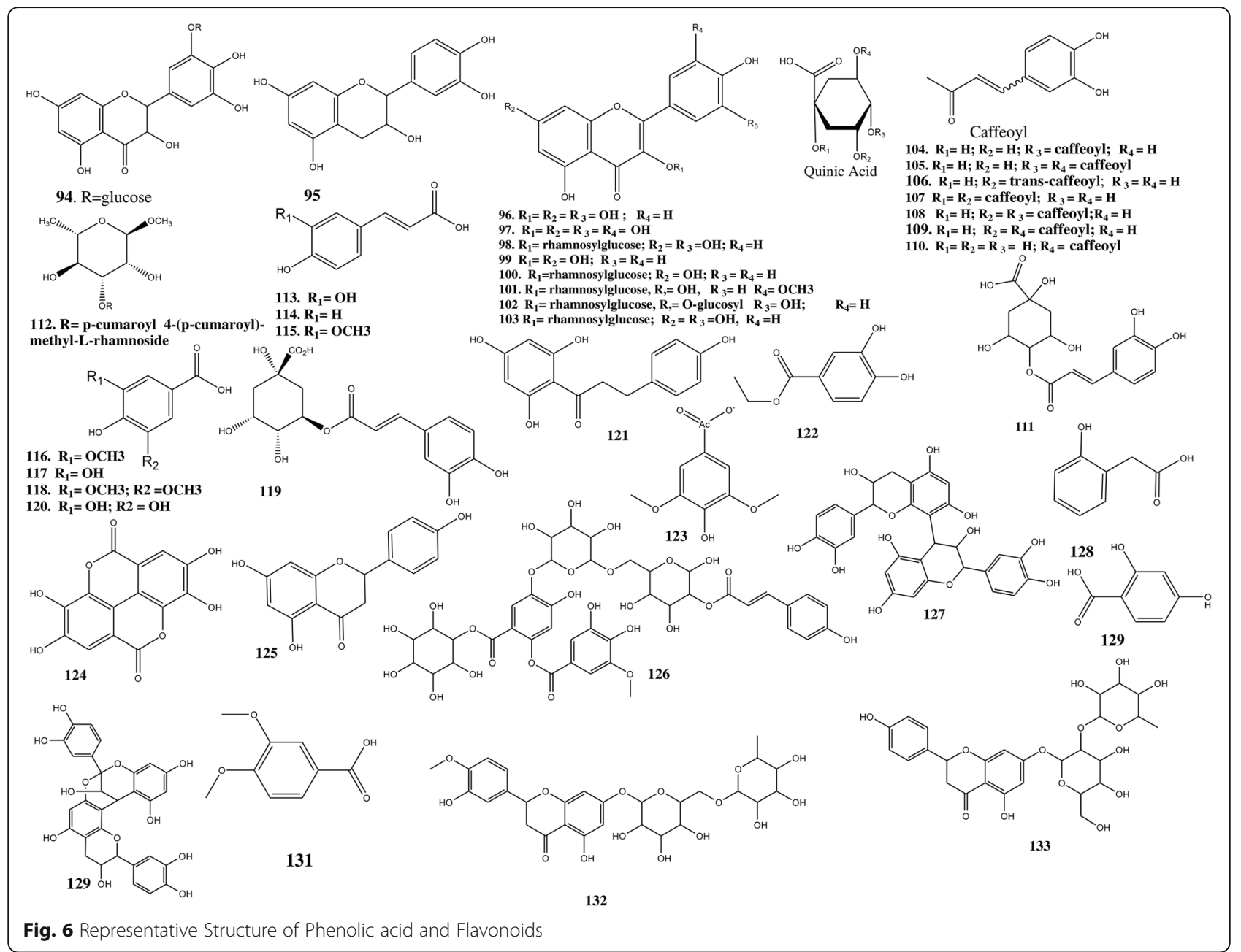

et al. consumption of anthocyanin-rich extract of $L$. ruthenicum Murr was shown to be cause significant reduction in body weight and decrease in the Lee's index along with elevation of serum HDLC, fecal fatty acid content, SOD activities besides reduction in MDA and hepatic lipids. Anti-inflammatory efficacy was shown with marked down-regulation of established pro-inflammatory markers; TNF- $\alpha$, IL-6, NF$\kappa \mathrm{B}, \mathrm{IFN}-\gamma$ and iNOS. The authors claimed that black wolfberry anthocyanins potentially alleviate dietinduced obesity by regulating accelerating fat decomposition, inflammation, oxidative stress [88].

Table 9 Coumarins and Cinamate derivatives

\begin{tabular}{lll}
\hline S.No & Coumarins and Cinamate & References \\
\hline 134. & Methyl-2-hydroxy-4-undecanoxy-trans- cinamate & {$[57]$} \\
135. & Scopoletin & {$[57]$} \\
136. & Esculetin & {$[57]$} \\
\hline
\end{tabular}

\section{Neuroprotective effects}

Neurodegenerative diseases like Alzheimer's are associated with progressive cognitive dysfunction and neuronal damage and have become a clinical challenge with modern- daylifestyle. Neuro-protective phyto-compound rich functional foods are in vogue in consideration with the rampant emergence of progressive neurodegenerative diseases worldwide. Several pre-clinical studies have unfolded the promising neuroprotective efficacy of $L$. ruthenicum Murr fruits and offered compelling evidences for biological activity. Lycium ruthenicum Murr anthocyanin extract has shown promise in an animal model of amyloid beta-protein 1-42 induced Alzheimer's disease. The extract at a dose of $80 \mathrm{mg} / \mathrm{kg}$, could improve the animal's memory capacity in a passiveavoidance test in a shuttle box and significantly reduce markers of neuronal oxidative stress and inflammation in the hippocampus tissue of the rat brain [70, 89]. In the following years, Chen et al [69] re-validated and suggested an underlying biological mechanism for the protective benefits of L. ruthenicum Murr anthocyanins in 


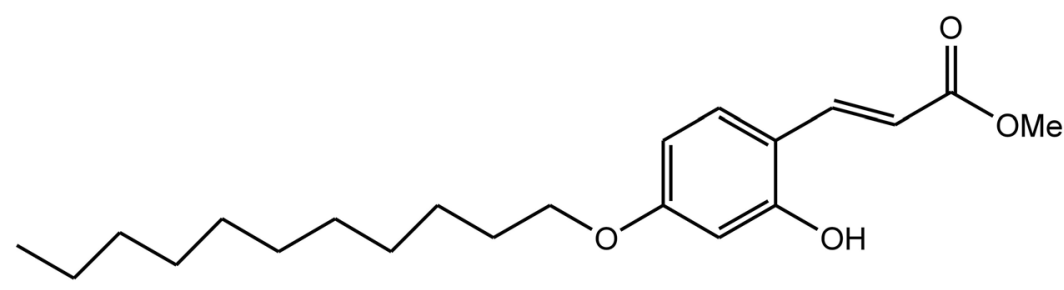

134<smiles>[R6]c1cc2ccc(=O)oc2cc1O</smiles>

135. $R=$ OMe

136.. $R=H$

Fig. 7 Representative Structure of Coumarins and Cinamate derivatives

an animal model of d-galactose induced memory impairment. In their study, anthocyanins were shown to lower the $\mathrm{Bax} / \mathrm{Bcl}-2$ ratio, caspase-3, C-jun $\mathrm{N}$-terminal kinase (p-JNK) levels with evident alleviation of memory dysfunction and neuroinflammation in an animal model.

Hypoxia is the hallmark of most neurodegenerative diseases. Preclinical evidence has been generated to show that black gojiberry extracts could protect the cortical neurons against conditions of oxygen-glucose deprivation/reperfusion. In a recent study, the specific activity of polysaccharide 3 (LRP3) of $L$. ruthenicum Murr was evaluated in an animal model of hypoxicischemic encephalopathy. LRP3 pre-treatment could induce expression of protective nuclear factor erythroid 2related factor (Nrf2) and heme oxygenase-1 (HO-1). The specificity of protection was shown by reversal of protection by s-RNA based inhibition Nrf2/HO-1 pathway [90]. Based on existing knowledge, very recently a network of L.ruthenicum Murr chemicals, putative biological targets and major pathways of Alzheimer's disease has been produced. Interestingly, in this pathbreaking study, 12 core genes have been identified which are potentially modulated by Lycium ruthenicum Murr extract and could be responsible for its potent activities [91]. Such studies are set to give most sought after answer to biological mechanisms behind the plethora of observed biological efficacies of black goji berries.

\section{Gastrointestinal (GI) activity}

In an in-vitro digestion stimulation study, anthocyanins from L. ruthenicum Murr have been reported to positively impact intestinal health both by encouraging the growth of health- promoting human gut microbiota as well as biosynthesis of short-chain fatty acids (SCFAs) during in-vitro fermentation [92]. It is reported earlier that gut microbiota participates in anthocyanin metabolism and absorption; in turn anthocyanin metabolites have pro-biotic activities for maintenance of healthy gut microbiota [93]. Anthocyanins significantly increased the relative abundances of Bifidobacterium and Allisonella, and reduced the relative abundances of Prevotella,
Dialister, Megamonas and Clostridium. In proof of concept in-vivo study by Peng et al [94], prolonged treatment of mice with crude extract of anthocyanins from $L$. ruthenicum Murr fruits, showed its positive effect of strengthening intestinal barrier (via. Upregulation of barrier proteins Zo-1, Occludin, Claudin-1 and Muc1) and proliferation of gut microbiota (Coprobacter, Barnesiella, Eisenbergiella, Alistipes, and Odoribacter). This was a recapitulation and validation of findings by Luo et al [91] wherein C57BL/6 mice fed with L. ruthenicum Murr showed significant enrichment of fecal microbiota and SCFAs along with improved intestinal immune barrier functions, reduced permeability, free ammonia etc in comparison to the antibiotic treatment group.

\section{Hypoglycemic effect}

Very limited evidence of the hypoglycemic effect of $L$. ruthenicum Murr fruits is available in the scientific literature. In a study by Wang et al., the antihyperglycemic efficacy of polysaccharide extracts of $L$. ruthenicum Murr fruits was evaluated in alloxan- induced diabetes model in mice. In this study, 21 days of polysaccharide extract supplementation could downregulate hyperglycemia and restored conversion of blood glucose into liver glycogen reserves along with lowering of oxidative damage markers [95].

\section{Antifatigue effect}

The polysaccharides from medicinal plants have been reported as natural anti-fatigue substances by several researchers [54, 96-99]. Different doses of water-soluble polysaccharides from L. ruthenicum Murr (50, 100 and $200 \mathrm{mg} / \mathrm{kg}$ ) have been tested for anti-fatigue activity in a rodent model of forced swim test (FST) [96]. The highest dose showed promising anti-fatigue activity based on standard fatigue markers such as lactic dehydrogenase, blood urea nitrogen, triglycerides, creatine phosphokinases etc. Plausible underlying mechanisms are proposed to be triglyceride mobilization for energy generation and upregulation of anti-oxidant activity markers such as GSH, GPx and SOD [19]. In a study of anti-fatigue and 
Table 10 Identified Anthocyanins of Black Goji Berry

\begin{tabular}{|c|c|c|}
\hline S.No & Name & Reference \\
\hline 137. & Peonidin 3-O-[6-O-(4-O-E-p-coumaroyl-O-a-rhamnopyranosyl)- $\beta$-glucopyranoside]-5-O- $\beta$ - glucopyranoside & [62] \\
\hline 138. & Petunidin 3-O-[6-O-(4-O-trans-p-coumaroyl-O- $\alpha$ - rhamnopyranosyl)- $\beta$-glucopyranoside]-5-O- $\beta$ - glucopyranoside & {$[3,41]$} \\
\hline 139. & Petunidin 3-O-[6-O-(4-O-(cis-p coumaroyl)-a-L- rhamnopyranosyl)- $\beta$-D-glucopyranoside]-5-O-[ $\beta$ - D-glucopyranoside] & {$[41,42]$} \\
\hline 140. & Petunidin 3-O-[6-O-(4-O-(trans-p-caffeoyl)-a-L- rhamnopyranosyl)- $\beta$-D-glucopyranoside]-5-O-[3-D-glucopyranoside] & {$[41,42]$} \\
\hline 141. & $\begin{array}{l}\text { Petunidin 3-O-[6-O-(4-O-(4-O-trans-( } \beta \text {-D- glucopyranoside)-p-coumaroyl)-a-L rhamnopyranosyl)- } \beta \text {-D-glucopyranoside]- } \\
\text { 5-O-[ } \beta \text { - D-glucopyranoside]. }\end{array}$ & {$[41,42]$} \\
\hline 142. & 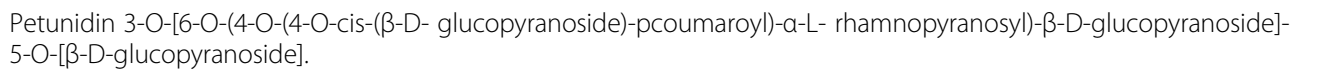 & {$[41,42]$} \\
\hline 143. & Petunidin 3-trans-caffeoylrutinoside-5-glucoside & [67] \\
\hline 144. & Petunidin-3-feruloylrutinoside-5-glucoside & [67] \\
\hline 145. & Petunidin 3-cis-p-coumaroylrutinoside-5-glucoside & {$[25,63,68]$} \\
\hline 146. & Petunidin 3-trans-p-coumaroylrutinoside-5-glucoside & {$[25,42,63,67,68]$} \\
\hline 147. & Petunidin 3-rutinoside-5-glucoside & [67] \\
\hline 148. & Petunidin 3-O-rutinoside (glucosyl-cis-p-coumaroyl)-5-O- glucoside & {$[25,68]$} \\
\hline 149. & Petunidin 3-O-rutinoside (glucosyl-trans-p-coumaroyl)-5-O- glucoside & {$[25,68]$} \\
\hline 150. & Pentuidin-3-O-(caffeoyl)-rutinoside-5-O-glucoside & [66] \\
\hline 151 & Petunidin-3-O-(glucosyl-p-coumaroyl)-rutinoside-5-O-glucoside & [66] \\
\hline 152 & petunidin-3-O-(p coumaroyl)-rutinoside-5-O-glucoside & [66] \\
\hline 153. & Delphinidin 3-glucosyl-trans-p-coumaroylrutinoside-5-glucoside & [42] \\
\hline 154. & 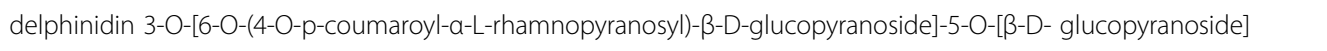 & [69] \\
\hline 155. & Delphinidin 3-cis-p-coumaroylrutinoside-5-glucoside & {$[25,42,63,68]$} \\
\hline 156 & Delphinidin 3-trans-p-coumaroylrutinoside-5-glucoside & {$[25,42,63,68]$} \\
\hline 157 & Malvidin-3-glucosyl-cis-p-coumaroylrutinoside-5-O-glucoside & [42] \\
\hline 158 & Malvidin-3-glucosyl-trans-p-coumaroylrutinoside-5-O-glucoside & [42] \\
\hline 159. & Malvidin-3-O-(p-coumaroyl)-rutinoside-5-O-glucoside & [66] \\
\hline 160. & Malvidin-3-rutinoside-(feruloyl)-5-O-glucoside & {$[25,42]$} \\
\hline 161. & Malvidin-3-O-rutinoside-5-O-glucoside & [42] \\
\hline 162. & Malvidin-3-cis-p-coumaroylrutinoside-5-O-glucoside & {$[25,42,63,68]$} \\
\hline 163. & Malvidin-3-trans-p-coumaroylrutinoside-5-O-glucoside & {$[42,67]$} \\
\hline 164 & Cyanidin-3-O-glucoside & {$[25,67]$} \\
\hline 165 & Cyanidin-3-O-galactoside & [25] \\
\hline 166 & Cyanidin-3, 5-O-diglucoside & [25] \\
\hline 167. & Cyanidin-3-O-rutinoside & [66] \\
\hline 168 & Pelargonidin - 3-O-glucoside & {$[25,33]$} \\
\hline 169. & Pelargonidin - 3-O-galactoside & [25] \\
\hline 170. & Pelargonidin-3-O-diglucoside & [25] \\
\hline 171. & Petunidin-3, 5-O-diglucosides & [25] \\
\hline 172. & petunidin-3-glucoside & [33] \\
\hline 173 & Petundin-3-O-glucoside-5-O-glucoside & {$[25,63,68]$} \\
\hline 174 & Petundin-3-O-galactoside-5-O-glucoside & {$[25,63,68]$} \\
\hline 175 & Pentunidin-3-O-glucoside-(feruloyl)-5-O- glucoside & {$[25,68]$} \\
\hline 176. & Pentunidin-3-O-glucoside-(maloyl)-5-O-glucoside & {$[25,68]$} \\
\hline 177. & malvidin-3-glucoside & [33] \\
\hline 178. & peonidin-3-glucoside & [33] \\
\hline 179 & Delphinidin-3-glucoside & [33] \\
\hline
\end{tabular}


Table 10 Identified Anthocyanins of Black Goji Berry (Continued)

\begin{tabular}{lll}
\hline S.No & Name & Reference \\
\hline 180 & Delphinidin -3-O-(6'-p-coumaryl)-Glucoside & {$[25]$} \\
181. & Malvidin & {$[33]$} \\
182. & Cyanidin & {$[33]$} \\
183. & Petunidin & {$[33]$} \\
184. & Pelargonidin & {$[33]$} \\
185 & Peonidin & {$[33]$} \\
\hline
\end{tabular}

myocardial protection by L. ruthenicum extract (extracts $0.10,0.1,0.15 \mathrm{~g} / \mathrm{mL}$, drug dose $0.1 \mathrm{ml} / 10 \mathrm{~g}$ ), American Ginseng powder $(0.05 \mathrm{~g} / \mathrm{mL})$ was used as a positive control. L. ruthenicum Murr extract could extend the weight loaded swimming time, decreased blood lactic acid and urea nitrogen levels along with enhanced muscle and liver glycogen reservoirs [67]. Improved anti-fatigue effect of microcapsules loading of L. ruthenicum Murr anthocyanidins by modified b-glucan from highland barley has also been shown [100]. Some experimental results demonstrate that L. ruthenicum Murr can increase blood sugar, reduce lactic acid content and increase glycogen reserve in mice, which has good alleviating resistance to exercise-induced fatigue [32].

\section{Radioprotective effects}

In a mice model of radiation- induced injury, L. ruthenicum Murr extract (dose $2 \mathrm{~g} / \mathrm{kg}$ and $4 \mathrm{~g} / \mathrm{kg}$ ) shows a reduction in caspase- 3 and caspase- 6 expression following $5 \mathrm{~Gy}$ irradiation. This was also associated with a significant increase in total red blood cells, DNA and hemoglobin content in comparison with the standard drug control group amifostine (WR-27212015) [101].

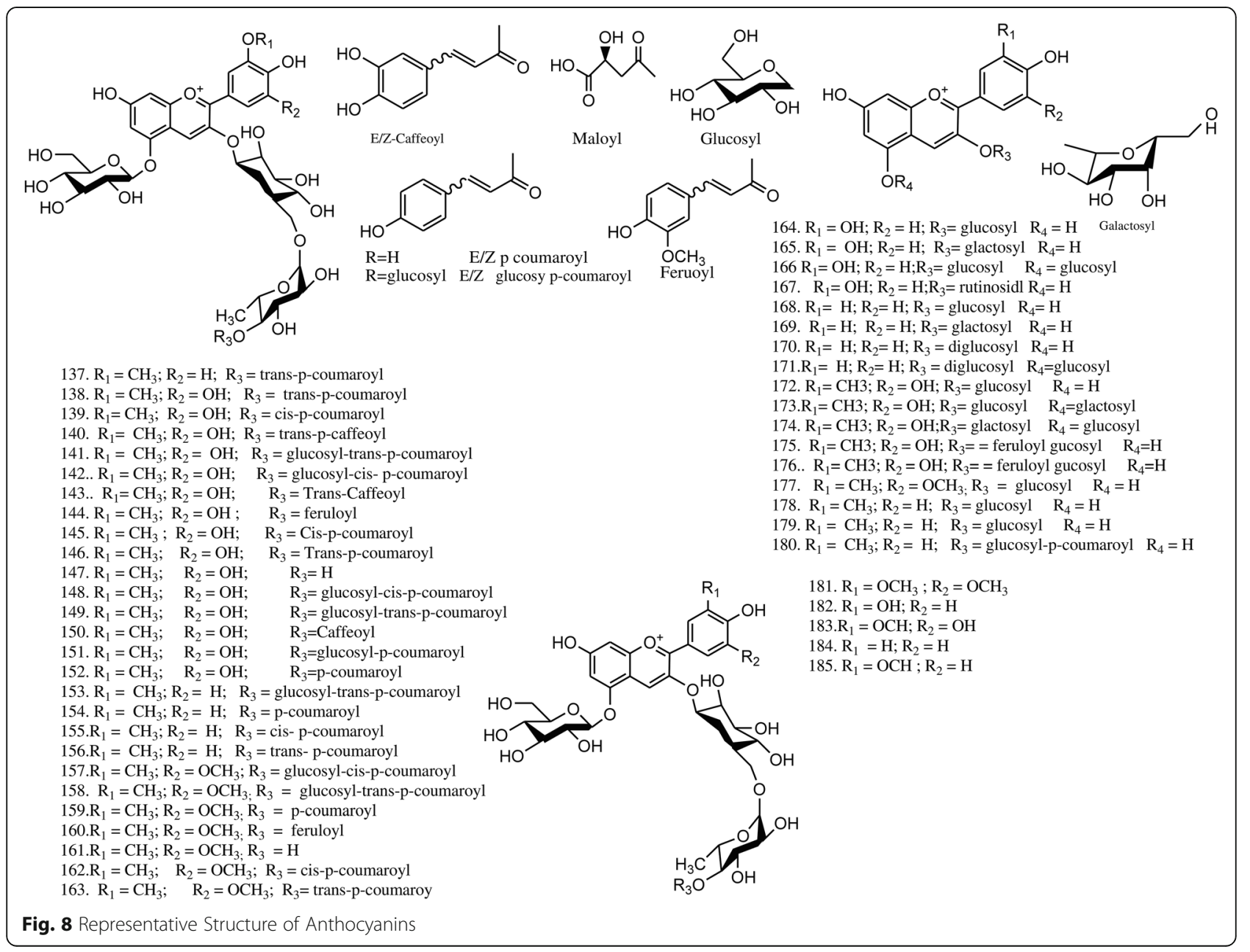




\section{Immuno-modulatory effects}

The pectin content of $L$. ruthenicum Murr has been proposed to be responsible for its observed immunomodulatory efficacy. In an in-vitro study, Peng et al. [37] have shown immunomodulatory functions of isolated pectin from L. ruthenicum Murr in mouse macrophage RAW264.7 cell line. The results indicated that treatment with pectin stimulated the macrophages to produce a higher level of NO which is the mediator in the regulation of immunological functions. In an in-vivo evaluation, the efficacy of its polysaccharide preparation (LRGP3) has been tested in a mouse model of cyclophosphamide-induced immunosuppression [102]. Administration of all the doses $(25,50$ and $100 \mathrm{mg} / \mathrm{kg})$ for 10 days boosted recovery of indices in thymus and spleen, $\mathrm{B}$ and $\mathrm{T}$ cell proliferation, phagocytic activities of peritoneal macrophages, restoration of cytokine profile.

\section{Hepatoprotective effects}

Treatment of high-fat-diet fed C57/BL mice with $L$. ruthenicum Murr fruit extract ( $2 \mathrm{~g} / \mathrm{kg}$ and $5 \mathrm{~g} / \mathrm{kg}$ doses) has been shown to have hepatoprotective effects by regulation of AMPK signaling pathway. L. ruthenicum Murr extract supplementation could downregulate fatty acid synthase and sterol regulatory element-binding protein $1 \mathrm{c}$ along with upregulation of peroxisome proliferator -activated receptor $\alpha$ and peroxisome proliferator activated receptor $\gamma$ coactivator $1 \alpha$. This also co-existed with significantly reduced triglycerides, total cholesterol, aspartate aminotransferase and alanine aminotransferase in the serum, improved glucose metabolism and insulin sensitivity in NAFLD mice [103].

\section{Toxicology and adverse reactions}

Like most other commonly consumed wild fruits, $L$. ruthenicum Murr is also proposed to be non-toxic and has been used traditionally as food as well as herbal medicine without any observed or reported toxicity. A Chinese study, about the toxicological investigations on this plant has concluded $L$. ruthenicum Murr fruit as non-toxic. In this study, acute toxicity test, Ames test, bone marrow cell micronucleus, sperm shape abnormality test, thirty days feeding test were conducted. The MTD of L. ruthenicum Murr pigment growth in mice and rats was found greater than $30,000 \mathrm{mg} /(\mathrm{kg} . \mathrm{bw})$ and thus claimed safe for consumption. Also, the mutagenic test was found negative and no abnormal phenomenon was observed in rats after being fed for 90 days. Interestingly, anthocyanin enriched herbal extracts of black gojiberries showed activity for the treatment of chronic myeloid leukemia (CML) [104]. Biological activity tests showed that LRP3-S1 could inhibit the growth of pancreatic cancer cells. Also, LRP3-S1 could attenuate the invasion ability of BxPC- 3 cells and downregulate protein expression of $\mathrm{p}-\mathrm{FAK}, \mathrm{p}-\mathrm{AKT}, \mathrm{p}-\mathrm{GSK}-3 \beta$ and p-p38 MAP kinase [33].

\section{Natural colorant}

In recent years, the use of natural pigments has remarkably increased in the food color industry due to growing awareness of the environmental hazards and the potential side effects of the synthetic chemicals being used as food colorants. Thus, many researchers are exploring the potentials of black goji berries to be used as a natural food grade blue color across wide range of $\mathrm{pH}$ conditions. Petunidin-3-trans-p-coumaroyl-rutinoside-5-glucoside is proposed to be the biggest contributor in color of black gojiberry $[105,106]$.

\section{Future perspective}

Phytochemical studies of L. ruthenicum Murr have revealed the presence of more than a hundred compounds. The crude extracts and some of the purified constituents of the black goji berry are reported to possess plethora of biological activities as well. Chiefly, the significantly higher content of anthocyanins, polysaccharides, spermine and spermidine alkaloids are accounted for most of these biological activities. Black goji berry has been used in the traditional medicinal system without any reported toxicity. The altitudes at which this plant is known to grow wildly, acute mountain sickness (AMS) is a predominant health concern to the sojourners that can further lead to potentially life threatening altitude illnesses such as High Altitude Cerebral Oedema (HACE) and High Altitude Pulmonary Oedema (HAPE). Oxidative stress, inflammatory stress and nitrosative stress are the main underlying causes behind high altitude sickness. Since black goji berry possess strong anti inflammatory, anti-fatigue and antioxidant activities, it deserves to be explored for its utility for development of a range of pharmaceuticals, cosmetics, food additives and nutraceutical products for curing diseases and general maintenance of well being at high altitude. Additionally, owing to its enriched content of photo-stable and thermo-stable anthocyanins, the plant has tremendous applications as natural food colorant. There are ample research opportunities to explore the phyto-chemistry, biological activities and safety for development of quality products from Lycium ruthenicum Murr with wide applications (Fig. 9). Hence, from the above mentioned reports it can be concluded that L. ruthenicum Murr has immense potential to cure various diseases and this less explored but high value medicinal plant of Indian TransHimalaya, particularly Ladakh has enormous importance in traditional system of medicine (Amchi System of Medicine). Although a lot of exploration has been done, still there is a need of in-depth scientific validation of its biological activities and underlying biological mechanisms for bio-active components of this plant for development of herbal preparations/ products. 


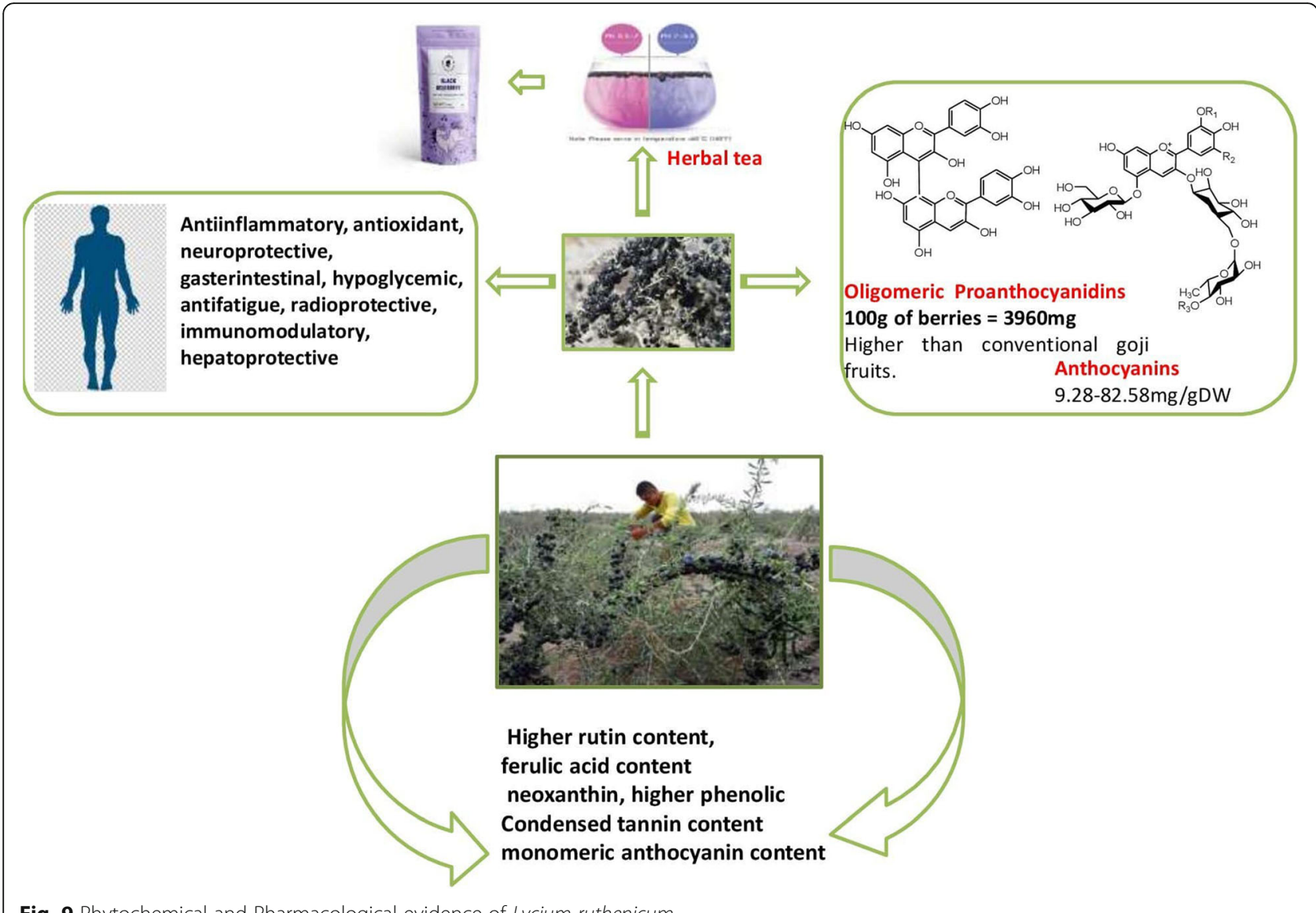

Fig. 9 Phytochemical and Pharmacological evidence of Lycium ruthenicum

\section{Conclusions}

We have critically reviewed the bioactive components and their biological activities from L.ruthenicum Murr with their respective structures. A unique color of anthocyanins reported from black goji berries possesses most of the pharmacological activities which makes L.ruthenicum Murr, a good candidate for exploration of therapeutic properties.

\section{Abbreviations}

ABTS: 2,2'-azino-bis-3-ethylbenzothiazoline-6-sulphonic acid; DW: Dry weight; Dhc: Dihydrocaffeoyl; DPPH: 2,2-diphenyl-1-picrylhydrazyl; FW: Fresh weight; FRAP: Ferric reducing/antioxidant power; GAE: Gallic Acid Equivalent; iNOS: inducible nitric oxide synthase; IL: Interleukin; NF-kB: Nuclear factor KB; ROS: Reactive oxygen species; SOD: Superoxide dismutase; TPC: Total phenolic content; TFC: Total flavonoid content; TE: Tanin equivalent; TNFa: Tumor necrosis factor-a; VE: Vitamin E

\section{Acknowledgements}

We would like to dedicate this article to the ethnic communities who perfected and preserved the traditional knowledge about health promoting properties of the genus lycium.

\section{Authors' contributions}

All authors contributed equally to literature research, writing manuscript etc. The author(s) read and approved the final manuscript.

\section{Funding}

This work was supported by the Defence Institute of High Altitude ResearchDefence Research Development Organization.

Availability of data and materials Not applicable.

\section{Declarations}

Ethics approval and consent to participate Not applicable.

\section{Consent for publication}

The authors consent for the publication of this review.

Competing interests

The authors declare that they have no potential conflicts of interest.

\section{Author details}

'Defence Institute of High Altitude Research (DIHAR), Defence Research and Development Organization DRDO), Ministry of Defence, C/o 56 APO,

Leh-Ladakh, Jammu \& Kashmir 901205, India. ${ }^{2}$ Medicinal Chemistry Division, Indian Institute of Integrative Medicine (CSIR), Canal Road, Jammu 180001, India.

Received: 26 March 2021 Accepted: 15 November 2021 Published online: 11 January 2022

\section{References}

1. Hong DY, Pan KY, Nicholas JT. Flora of China. 6th ed. Beijing: Science Press; 2001. p. 127-32. 
2. Qian D, Zhao Y, Yang G, Huang L. Systematic review of chemical constituents in the genus Lycium (Solanaceae). Molecule. 2017;22(6):911. https://doi.org/10.3390/molecules22060911.

3. Wang H, Li J, Tao W, Zhang X, Gao X, Yong J, et al. Lycium ruthenicum studies: Molecular biology, Phytochemistry and pharmacology. Food Chem. 2018;240:759-66.

4. Dhar P, Tayade A, Ballabh B, Chaurasia OP, Bhatt RP, Srivastava RB. Lycium ruthenicum murray: a less-explored but high value medicinal plant from trans-himalayan cold deserts of Ladakh, India. Plant Archives. 2011;11:583-6.

5. Chaurasia OP, Ahmed Z, Ballabh B. Ethnobotany and plants of transHimalaya. New Delhi: SSPL; 2007.

6. Kuang KZ, Lu AM, Wu CY, Huang SC. Solanaceae. Flora Reipublicae Popularis Sinicae. 1978;67:1-175.

7. Tutin TG, Heywood VH, Burges NA, Moore DM, Valentine DH, Walters SM, et al. Flora Europaea, vol. 3. Cambridge: Cambridge University Press; 1972. p. 89-94.

8. Gregor RL. Barkley TM. Kansas: Flora of the great plains University Press of Kansas; 1986.

9. Zhang HF, Li X, Wang JG, Yang YJ. The structure characteristic of the plant community in the lower reaches of Tarim River. Ecol Environ. 2007;16:1219-24.

10. Zhang X, Zhang F, Gao XJ, Yong JJ, Zhang WH, Zhao JJ, et al. Effects of different drying methods on content of bioactive component and antioxidant activity in Lycium ruthenicum. Zhongguo Zhong yao za zhi. China J Chin Mat Med. 2017;42(20):3926-31. https://doi.org/10.19540/j.cnki. cjcmm.20170907.011.

11. Dierma D, Mao J. Crystal pearl of materia medica. Shanghai: Shanghai Scientific and Technical Publishers; 2012. p. 66.

12. Chaurasia, OP, Singh B. Cold desert plants Field Research Laboratory, LehLadakh, 1996-2001: Vol-I-V.

13. Yutuo Y. Medical canon in four sections, vol. 321. Shanghai: Shanghai Scientific and Technical Publishers; 1987

14. Liu YM. Pharmacography of Uighur part one Xinjiang Science \& Technology \& hygiene publishing house, Urumqi,1999.

15. Ballabh B, Chaurasia OP, Ahmed Z, Singh SB. Traditional medicinal plants of cold desert Ladakh--used against kidney and urinary disorders. J Ethnopharmacol. 2008;118(2):331-9. https://doi.org/10.1016/j.jep.2008.04.022.

16. Chopra RN, Nayar SL, Chopra IC. Glossary of Indian medicinal plants (including the supplement). New Delhi: Council of Scientific and Industrial Research; 1986.

17. Gairola S, Sharma J, Bedi YS. A cross-cultural analysis of Jammu, Kashmir and Ladakh (India) medicinal plant use. J Ethnopharmacol. 2014;155(2):925-86. https://doi.org/10.1016/j.jep.2014.06.029.

18. Nzeuwa IB, Xia Y, Qiao Z, Feng F, Bian J, Liu W, et al. Comparison of the origin and phenolic contents of Lycium ruthenicum murr. By highperformance liquid chromatography fingerprinting combined with quadrupole time-of-flight mass spectrometry and Chemometrics. J Sep Sci. 2017;40(6):1234-43. https://doi.org/10.1002/jssc.201601147.

19. Ni W, Gao T, Wang H, Du Y, Li J, Li C, et al. Anti-fatigue activity of polysaccharides from the fruits of four Tibetan platea indigenous medicinal plants. J Ethnopharmacol. 2013;150(2):529-35. https://doi.org/10.1016/j.jep.2 013.08.055.

20. Quan SH, Hai-xia ZH, Yu L, Yan L. The research on chemical component and antioxidant activity of wild Lycium ruthenicum. Sci Technol Food Ind. 2017:4:10.

21. Zhao W, Song Y, Zhou G. Study on Proanthocyanidin-rich beer. J Am Soc Brew. 2017;75(2):109-15. https://doi.org/10.1094/ASBCJ-2017-2186-01.

22. Chi X, Xiao Y, Dong Q, Yang YQ, Hu F. Fatty acid composition of Lycium ruthenicum collected from the Qinghai- tibetan plateau. Chem Nat Compd. 2016;54(4):674-5. https://doi.org/10.1007/s10600-016-1737-x.

23. Peng Y, Ma C, Li Y, Leung KS, Jiang ZH, Zhao ZZ. Quantification of zeaxanthin dipalmitate and total carotenoids in Lycium fruits (Fructus Lycii). Plant Foods Hum Nutr. 2005;60(4):161-4. https://doi.org/10.1007/s11130005-9550-5.

24. Islam T, Yu X, Badwal TS, Xu B. Comparative studies on phenolic profiles, antioxidant capacities and carotenoid contents of red goji berry (Lycium barbarum) and black goji berry (Lycium ruthenicum). Chem Cent J. 2017; 11(1):59. https://doi.org/10.1186/s13065-017-0287-z.

25. Tian Z, Aierken A, Pang H, Du S, Feng M, Ma K, et al. Constituent analysi and quality control of anthocyanin constituents of dried Lycium ruthenicum Murray fruits by HPLC-MS and HPLC-DAD. J Liq Chromatogr Relat Technol. 2016;39(9):453-8. https://doi.org/10.1080/10826076.2016.1179201.
26. Pantelidis GE, Vasilakakis M, Manganaris GA, Diamantidis G. Antioxidant capacity, phenol, anthocyanin and ascorbic acid contents in raspberries, blackberries, red currants, gooseberries and cornelian cherries. Food Chem. 2007;102(3):777-83. https://doi.org/10.1016/j.foodchem.2006.06.021.

27. Bajpai KP, Warghat AR, Sharma KR, Yadav A, Thakur KA, Srivastava RB, et al. Structure and genetic diversity of natural populations of Morus alba in the trans-Himalayan Ladakh region. Biochem Genet. 2014;52(3-4):137-52. https://doi.org/10.1007/s10528-013-9634-5.

28. López OP, Cervantes ML, Pérez MV, Pérez TH. Berries: improving human health and healthy aging, and promoting quality life -a review. Plant Foods Hum Nutr. 2010;65(3):299-308. https://doi.org/10.1007/s11130-0100177-1.

29. Stanciu G, Lupsor S, Sava C, Zagan S. Spectrophotometric study on stability of anthocyanins extracts from black grapes skins. Ovidius Univ Ann Ser Chem. 2010;21(1):101-4.

30. Liu B, Xu Q, Sun Y. Black goji berry (Lycium ruthenicum) tea has higher phytochemical contents and in vitro antioxidant properties than red goji berry (Lycium barbarum) tea. Food Qual Saf. 2020;4(4):193-201. https://doi. org/10.1093/fqsafe/fyaa022.

31. Jiao XL, Chi XF, Dong Q, Xiao YC, Fengzu HU. Analysis of the nutritional components of Lycium ruthenicum. Amino Acids Biotic Resour. 2011;03:60-2.

32. Xing $X, K e Y$. Nutritional value of Lycium ruthenicum Murr. And its relieving resistance to exercise-induced fatigue. Prog Nutr. 2019;21:876-81.

33. Zhang S, He F, Chen X, Ding K. Isolation and structural characterization of a pectin from Lycium ruthenicum Murr and its anti-pancreatic ductal adenocarcinoma cell activity. Carbohydr Polym. 2019;223:115104. https://doi. org/10.1016/j.carbpol.2019.115104.

34. Peng Q, Lv X, Xu Q, Li Y, Huang L, Du Y. Isolation and structural characterization of the polysaccharide LRGP1 from Lycium ruthenicum. Carbohydr Polym. 2012; 90(1):95-101. https://doi.org/10.1016/j.carbpol.2012.04.067.

35. Peng Q, Song J, Lv X, Wang Z, Huang L, Du Y. Structural characterization of an arabinogalactan-protein from the fruits of Lycium ruthenicum. J Agric Food Chem. 2012;60(37):9424-9. https://doi.org/10.1021/jf302619c.

36. LV X, Wang C, Cheng Y, Huang L, Wang Z. Isolation and structura characterization of a polysaccharide LRP4-a from Lycium ruthenicum Murr. Carbohydr Res. 2013;365:20-5. https://doi.org/10.1016/j.carres.2012.10.013.

37. Peng $Q, X u$ Q, Yin $H$, Huang $L$, Du Y. Characterization of an immunologically active pectin from the fruits of Lycium ruthenicum. Int J Biol Macromol. 2014;64:69-75. https://doi.org/10.1016/j.jibiomac.2013.11.030.

38. Liu Y, Gong G, Sun Y, Gu X, Huang L, Wang Z. Isolation, structural characterization, and immunological activity of a polysaccharide LRLP4A from the leaves of Lycium ruthenicum. J Carbohyd Chem. 2006;35: 40-56.

39. Wang SQ, Liu B, Liu S, Xie SZ, Pan LH, Zha XQ, et al. Structural features of an acidic polysaccharide with the potential of promoting osteoblast differentiation from Lycium ruthenicum Murr. Nat Prod Res. 2018;34(16): 2249-54. https://doi.org/10.1080/14786419.2018.1452014.

40. Debnath B, Singh W, Das M, Goswami S, Singh KM, Maitic D, et al. Role of plant alkaloids on human health: a review of biological activities. Mater Today Chem. 2018;9:56-72. https://doi.org/10.1016/j.mtchem.2018. 05.001.

41. Wu T, LV H, Wang F. Wang Y characterization of polyphenols from Lycium ruthenicum fruit by UPLC-Q-TOF/MSE and their antioxidant activity in Caco2 cells. J Agri Food Chem. 2016;64(11):2280-8. https://doi.org/10.1021/acs.ja fc.6b00035.

42. Jin H, Zhao J, Zhou W, Shen A, Yang F, Liu Y, et al. Preparative separation of a challenging anthocyanin from Lycium ruthenicum Murr by two dimensional reversed-phase liquid chromatography/ hydrophilic interaction chromatography. RSC Adv. 2015;5(76):62134-41. https://doi.org/10.1039/ C5RA08713A.

43. Yang $X$, Lin S, Jia Y, Rehman F, Zeng S, Wang Y. Anthocyanin and spermidine derivative hexoses coordinately increase in the ripening fruit of Lycium ruthenicum. Food Chem. 2019;311:125874. https://doi.org/10.1016/j. foodchem.2019.125874.

44. Qi JJ, Yan YM, Cheng LZ, Liu BH, Qin FY, Cheng YX. A novel flavonoid glucoside from the fruits of Lycium ruthenicum. Molecules. 2018;23(2):325. https://doi.org/10.3390/molecules23020325.

45. Nzeuwa IB, Xia H, Shi Y, Yang C, Shah SM, Guo B, et al. Fatty acid and mineral contents of Lycium ruthenicum Murr and antioxidant activity against isoproterenol-induced acute myocardial ischemia in mice. Food Sci Nutr. 2020;8(2):1075-81. https://doi.org/10.1002/fsn3.1393. 
46. Zhao X, Dong B, Li P, Wei W, Dang J, Liu Z, et al. Fatty acid and phytosterol composition, and biological activities of Lycium ruthenicum Murr. Seed oil. J Food Sci. 2018;83:2448-56

47. Keys A, Anderson JT, Grande F. Prediction of serum cholesterol response of man to change in fats in the diet. Lancet. 1957;2(7003):959-66. https://doi. org/10.1016/S0140-6736(57)91998-0.

48. Jarouche M, Suresh $H$, Hennell J, Sullivan S, Lee S, Singh S, et al. The quality assessment of commercial Lycium berries using LC-ESI-MS/MS and Chemometrics. Plants (Basel). 2019;8(12):604. https://doi.org/10.3390/pla nts8120604.

49. Liu Y, Zeng S, Sun W, Wu M, Hu W, Shen X, et al. Comparative analysis of carotenoid accumulation in two goji (Lycium barbarum L. and L. ruthenicum Murr.) fruits. BMC Plant Biol. 2014;14(1):269. https://doi.org/10.11 86/s12870-014-0269-4.

50. Cai YZ, Luo Q, Sun M, Corke H. Antioxidant activity and phenolic compounds of 112 traditional Chinese medicinal plants associated with anticancer. J Life Sci. 2004;74(17):2157-84. https://doi.org/10.1016/j.lfs.2003.09.047.

51. Xin G, Zhu F, Du B, Xu B. Antioxidants distribution in pulp and seeds of black and red goji berries as affected by boiling processing. J Food Qual. 2017 Article ID 3145946. https://doi.org/10.1155/2017/3145946.

52. Zhang G, Chen S, Zhou W, Meng J, Deng K, Zhou H, et al. Rapid qualitative and quantitative analyses of eighteen phenolic compounds from Lycium ruthenicum Murray by UPLC-Q-Orbitrap MS and their antioxidant activity. Food Chem. 2018;269:150-6. https://doi.org/10.1016/j.foodchem.2018.06.132.

53. Jia Q, Zhang S, Zhang H, Yang X, Cui X, Su Z, et al. A comparative study on polyphenolic composition of berries from the Tibetan plateau by UPLC-QOrbitrap MS system. Chem Biodivers. 2020;17(4):1612-872. https://doi.org/1 $0.1002 / c b d v .202000033$

54. Chen X, Zhang G. Scavenging and anti-fatigue activity of Wu-Wei-Zi aqueous extracts. African J Microbiol Res. 2011;5:5933-40.

55. Zahradnik M. The production and application of fluorescent brightening agents. New York: John Wiley \& Sons; 1992. p. 164

56. Valizadeh H, Kordi FM, Kouhkan R, Bahadori MB, Farimani MM. Isolation and structure elucidation of coumarin and cinamate derivatives from Lycium ruthenicum Iran. Chem Commun. 2014;2:277-82.

57. Khoo HE, Azlan A, Tang TS, Lim MS. Anthocyanidins and anthocyanins: colored pigment as food, pharmaceutical ingredients, and the potential health benefits. Food Nutr Res. 2017;61(1):1361779. https://doi.org/10.1080/1 6546628.2017.1361779.

58. Mazza G, Miniati E. Types of anthocyanins. In: Anthocyanins in fruits, vegetables, and grains. FL, USA: CRC Press; 1993. p. 1-28.

59. Castañeda A, Pacheco HL, Páez E, Rodriguez J, Galán-Vidal CA. Chemical studies of anthocyanins: a review. Food Chem. 2009;113(4):859-71. https:// doi.org/10.1016/j.foodchem.2008.09.001.

60. Zeng S, Wu M, Zou C, Liu X, Shen X, Hayward A, et al. Comparative analysis of anthocyanin biosynthesis during fruit development in two Lycium species. Physiol Plant. 2014;150(4):505-16. https://doi.org/10.1111/ppl.12131.

61. Shuang Q, Zhang HX, Lu Y. The research on chemical component and antioxidant activity of wild Lycium ruthenicum. Sci Technol Food Ind. 2017; 04:94-100

62. Tang J, Yan Y, Ran L, Mi J, Sun Y, Lu L, et al. Isolation, antioxidant property and protective effect on PC12 cell of the main anthocyanin in fruit of Lycium ruthenicum Murray. J Funct Foods. 2017;30:97-107. https:/doi.org/1 0.1016/j.jf.2017.01.015

63. Chen C, Shao Y, Tao Y, Mei L, Shu Q, Wang L. Main anthocyanins compositions and corresponding H-ORAC assay for wild Lycium ruthenicum Murr. Fruits from the Qaidam Basin. J Pharm Techol Drug Res. 2013;2(1):110. https://doi.org/10.7243/2050-120X-2-1.

64. Jin H, Liu Y, Yang F, Wang J, Fu D, Zhang X. Characterization of anthocyanins in wild Lycium ruthenicum Murray by HPLC-DAD/QTOF-MS/ MS. Anal Methods. 2015;7(12):4947-56. https://doi.org/10.1039/C5AY00612K.

65. Zhang G, Chen S, Zhou W, Meng J, Deng K, Zhou H, et al. Anthocyanin composition of fruit extracts from Lycium ruthenicum and their protective effect for gouty arthritis. Ind Crop Prod. 2019;129:414-23. https://doi.org/1 0.1016/j.indcrop.2018.12.026.

66. Liu P, Li W, Hu Z, Qin X, Liu G. Isolation, purification, identification, and stability of anthocyanins from Lycium ruthenicum Murr from LWT. Food Sci Technol. 2020;126:109334. https://doi.org/10.1016/j.lwt.2020.109334.

67. Yang J-F, Wang Q, Sun J, Feng D-Z. Anti-fatigue and improvement effect of exhausting exercise-induced myocardial damage of aqueous extract from Lycium Ruthenicum murr. In mice. Sci Technol Food Ind. 2018;39(16):296-9.312.
68. Zheng J, Ding C, Wang L, Li G, Shi J, Li H, et al. Anthocyanins composition and antioxidant activity of wild Lycium ruthenicum Murr. From QinghaiTibet plateau. Food Chem. 2011;126:859-65.

69. Chen S, Zhou H, Zhang G, Meng J, Deng K, Zhou W, et al. Anthocyanins from Lycium ruthenicum Murr. Ameliorated d-galactose-induced memory impairment, oxidative stress, and Neuroinflammation in adult rats. J Agric Food Chem. 2019;20(11):3140-9. https://doi.org/10.1021/acs.jafc.8b06402.

70. Kelsey N, Hulick W, Winter A, Ross E, Linseman D. Neuroprotective effects of anthocyanins on apoptosis induced by mitochondrial oxidative stress. Nutr Neurosci. 2011;14(6):249-59. https://doi.org/10.1179/1476830511Y.0000000020.

71. Prior RL, Wu X. Anthocyanins: structural characteristics that result in unique metabolic patterns and biological activities. Free Radic Res. 2006;40(10): 1014-28. https://doi.org/10.1080/10715760600758522.

72. Liu Z, Dang J, Wang Q, Yu M, Jiang L, Mei L, et al. Optimization of polysaccharides from Lycium ruthenicum fruit using RSM and its antioxidant activity, Int J Biol Macromol. 2013;61:127-34. https://doi.org/10.101 6/j.ijbiomac.2013.06.042.

73. Song JL, Gao Y, Xu J. Protective effects of methanolic extract form fruits of Lycium ruthenicum Murr on 2, 2'-azobis (2-amidinopropane) dihydrochloride-induced oxidative stress in LLC-PK1 cells. Pharmacogn Mag. 2014:10(40):522. https://doi.org/10.4103/0973-1296.141790.

74. Li J, Zhao HY, Yuan H, Zhu CQ, Shi DH. Study on the pigment of Lycium ruthenicum Murr. Food Sci. 2006:27:146-51.

75. Castro V, Aierken A, Zhang X, Dias A. Comparative study of antioxidant potential and cytotoxic effects of methanolic extracts from Lycium barbarum and Lycium ruthenicum berries. Plant Med Int Open. 2017;5 01:Tu-PO.

76. Kosar M, Altintas A, Kirimer N, Baser KHC. Determination of the free radical scavenging activity of Lycium extracts. Chem Nat Compd. 2003;39(6):531-5. https://doi.org/10.1023/B:CONC.0000018104.98378.e2.

77. Fang Z, Zhang M, Wang L. HPLC-DAD-ESIMS analysis of phenolic compounds in bayberries (Myrica rubra Sieb. Et Zucc.). Food Chem. 2007; 100(2):845-52. https://doi.org/10.1016/j.foodchem.2005.09.024.

78. Shen M, Liu K, Liang Y, Liu G, Sang J, Li C. Extraction optimization and purification of anthocyanins from Lycium ruthenicum Murr. And evaluation of tyrosinase inhibitory activity of the anthocyanins. J Food Sci. 2020;85(3): 696-706. https://doi.org/10.1111/1750-3841.15037.

79. Liu Z, Liu B, Kang H, Yue H, Chen C, Jiang L, et al. Subcritical fluid extraction of Lycium ruthenicum seeds oil and its antioxidant activity. Int J Food Sci Technol. 2019;54(1):161-9. https://doi.org/10.1111/ijfs.13920.

80. Wang ZC, Tanzeela N, Sun L, Fang Z, Yan Y, Li D, et al. Effect of in vitro gastrointestinal digestion on the composition and bioactivity of anthocyanins in the fruits of cultivated Lycium ruthenicum Murray. CyTA-J Food. 2019;17(1):552-62. https://doi.org/10.1080/19476337.2019.1613449.

81. Wang Q, Kuang H, Su Y, Sun Y, Feng J, Guo R, et al. Naturally derived antiinflammatory compounds from Chinese medicinal plants. J Ethnopharmacol. 2013;146(1):9-39. https://doi.org/10.1016/j.jep.2012.12.013.

82. Du Z, Liu H, Zhang Z, Li P. Angtioxidant and anti- inflammatory activities of Radix Isatidis polysaccharide in murine alveolar macrophages. Int J Biol Macromol. 2013;58:329-35. https://doi.org/10.1 016/j.ijbiomac.2013.04.037

83. Peng Q, Liu H, Lei H, Wang X. Relationship between structure and immunological activity of an arabinogalactan from Lycium ruthenicum. Food Chem. 2016;194:595-600. https://doi.org/10.1016/j.foodchem.2015.08.087.

84. Lin L, Li J, Lv H, Ma Y, Qian Y. Effect of Lycium ruthenicum anthocyanins on atherosclerosis in mice. Zhongguo Zhong yao Za Zhi. J Chin Mat Med. 2012;37:1460-6

85. Hou CW, Chen IC, Shu FR, Feng $\mathrm{CH}$, Hung CT. Protective effect of supplementation with Lycium ruthenicum Murray extract from exhaustive exercise-induced cardiac injury in rats. Chin Med J (Engl). 2019;132(8):1005-6. https://doi.org/10.1097/CM9.0000000000000185. PMID: 30958451; PMCID: PMC6595767.

86. Zong S, Yang L, Park HJ, Li J. Dietary intake of Lycium ruthenicum Murray ethanol extract inhibits colonic inflammation in dextran sulfate sodiuminduced murine experimental colitis. Food Funct. 2020;11(4):2924-37. https://doi.org/10.1039/DOFO00172D.

87. Lu K, Wang J, Yu Y, Wu Y, He Z. Lycium ruthenicum Murr. Alleviates nonalcoholic fatty liver in mice. Food Sci Nutr. 2020;8(6):2588-97. https:// doi.org/10.1002/fsn3.1445.

88. Yin J, Wu T. Anthocyanins from black wolfberry (Lycium Ruthenicum Murr.) prevent inflammation and increase fecal fatty acid in diet-induced obese rats. RSC Adv. 2017;7:47848-53. 
89. Wu X, Li X, Liang S, Liu Y, Dai X, Zheng Q, et al. Neuroprotective Effect of Anthocyanin Extract from Lycium ruthenicum Murray in AB1-42-induced Rat Model of AD; 2017. https://doi.org/10.20944/preprints201705.0144.v1.

90. Deng K, Li Y, Xiao M, Wang F, Zhou P, Zhang W, et al. Lycium ruthenicum Murr polysaccharide protects cortical neurons against oxygen-glucose deprivation/ reperfusion in neonatal hypoxic-ischemic encephalopathy. Int J Biol Macromol. 2020;158:562-8. https:/doi.org/10.1016/j.j.jbiomac.2020.04.122.

91. Luo Z, Yu G, Chen X, Liu Y, Zhou Y, Wang G, et al. Integrated phytochemical analysis based on UHPLC-LTQ-Orbitrap and network pharmacology approaches to explore the potential mechanism of Lycium ruthenicum Murr. For ameliorating Alzheimer's disease. Food Funct. 2020;14(2):1362-72. https://doi.org/10.1039/C9FO02840D.

92. Yan Y, Peng Y, Tang J, Mi J, Lu L, Li X, et al. Effects of anthocyanins from the fruit of Lycium ruthenicum Murray on intestinal microbiota. J Funct Foods. 2018:48:533-41. https://doi.org/10.1016/j.jff.2018.07.053.

93. Faria A, Fernandes I, Norberto S, Mateus N, Calhau C. Interplay between anthocyanins and gut microbiota. J Agric Food Chem. 2014;62(29):6898902. https://doi.org/10.1021/j5501808a.

94. Peng $Y$, Yan $Y$, Wan $P$, Dong $W$, Huang $K$, Ran $L$, et al. Effects of long-term intake of anthocyanins from Lycium ruthenicum Murray on the organism health and gut microbiota in vivo. Food Res Int. 2020;130:108952. https:// doi.org/10.1016/j.foodres.2019.108952.

95. Wang JH, Chen $\mathrm{XQ}$, Zhang WJ. Study on hypoglycemic function of polysaccharides from Lycium ruthenicum Murr. Fruit and its mechanism. Food Sci. 2009;30:244-8.

96. Wang J, Li S, Fan Y, Chen Y, Liu D, Cheng H, et al. Anti-fatigue activity of the water-soluble polysaccharides isolated from Panax ginseng. J Ethnopharmacol. 2010;130(2):421-3. https://doi.org/10.1016/j.jep.2010.05.027.

97. Sheng R, Xu X, Tang Q, Bian D, Li Y, Qian C, et al. Polysaccharide of radix pseudo stellariae improves chronic fatigue syndrome induced by poly I:C in mice. Evid Based Complement Alternat Med. 2011;840516:1-9. https://doi. org/10.1093/ecam/nep208.

98. Hu JH, Yan F, Zhang ZY, Lin JY. Evaluation of antioxidant and anti-fatigue activities of Ganoderma lucidum polysaccharides. J Anim Vet Adv. 2012;11: 4040-4.

99. Tan W, Yu KQ, Liu YY, Ouyang MZ, Yan MH, Luo R, et al. Anti- fatigue activity of polysaccharides extract from Radix Rehmanniae Preparata. Inte J Biol Macromol. 2012;50(1):59-62. https://doi.org/10.1016/j.j.jbiomac.2011.09.019.

100. Gao Q, Shu T, Chang Y, Hu C, Cao X, Wang S. Evaluation of anti-fatigue function of solution of microcapsules loading anthocyanidins of Lycium ruthenicum murr by modified b-glucan from highland barley. Shipin Keji. 2019;44:316-20.

101. Duan Y, Chen F, Yao X, Zhu J, Wang C, Zhang J, et al. Protective effect of Lycium ruthenicum Murr. Against radiation injury in mice. Int J Environ Res Public Health. 2015;12:8332-47.

102. Gong Y, Wu J, Li ST. Immuno-enhancement effects of Lycium ruthenicum Mur. Polysaccharide on cyclophosphamide- induced immunosuppression in mice. Int J Clin Exp Med. 2015;8(11):20631-7.

103. Lin J, Zhang $Y$, Wang $X$, Wang W. Lycium ruthenicum extract alleviates high-fat diet-induced nonalcoholic fatty liver disease via enhancing the AMPK signaling pathway. Mol Med Rep. 2015;12(3):3835-40. https://doi. org/10.3892/mmr.2015.3840.

104. Li J, Yuan H, Zeng XC, Han B, Shi DH. Toxicological assessment of pigment of Lycium ruthenicum Murr. Food Sci. 2007;28:470-5.

105. Tang P, Giusti MM. Black goji as a potential source of natural color in a wide pH range. Food Chem. 2018;269:419-26. https://doi.org/10.1016/j. foodchem.2018.07.034.

106. Giusti MM, Peipei T. Uses of acylated anthocyanins extracted from black goji (lycium ruthenicum murr.) as a source of natural Color. 2017; PCT/US20 17/ 033290. W02017205173A1.

\section{Publisher's Note}

Springer Nature remains neutral with regard to jurisdictional claims in published maps and institutional affiliations.

\section{Submit your manuscript to a SpringerOpen ${ }^{\circ}$ journal and benefit from:}

- Convenient online submission

- Rigorous peer review

- Open access: articles freely available online

- High visibility within the field

- Retaining the copyright to your article

Submit your next manuscript at $\boldsymbol{\nabla}$ springeropen.com 